\title{
Assimilation of Geosat altimeter data into an eddy-resolving primitive equation model of the North Atlantic Ocean
}

\author{
Andreas Oschlies ${ }^{1}$ and Jürgen Willebrand \\ Institut für Meereskunde, Kiel, Germany
}

\begin{abstract}
We present a new method for assimilating observations of sea surface height (SSH) into a high-resolution primitive equation model. The method is based on the concept of reinitialization. First, the surface velocity increments necessary to adjust the model forecast to the observed geostrophic surface currents are projected onto deep velocity increments by a linear regression method. Second, changes in the density field required to balance the changes in the velocity field geostrophically are obtained from an inversion of the thermal wind equation. A unique partition of the density increments into corresponding temperature and salinity changes is realized by conserving the local $\theta-S$ relation of the model forecast. In contrast to pure statistical methods that infer temperature and salinity changes from correlations with SSH anomalies, our approach explicitly conserves water mass properties on isopycnals. For the assimilation experiment we use optimally interpolated maps of Geosat SSH anomalies (the mean topography is taken from the model), which are assimilated into the World Ocean Circulation Experiment (WOCE) Community Modeling Effort (CME) model of the North Atlantic Ocean at 5-day intervals covering the year 1987. It is shown that the assimilation significantly improves the model's representation of eddy activity, with the hydrographic structure of individual eddies agreeing well with independent hydrographic observations. The importance of a careful treatment of water mass properties in the assimilation process is discussed and further illustrated by comparing different assimilation schemes.
\end{abstract}

\section{Introduction}

One of the most important data sets for studying and monitoring the world ocean is presently provided by satellite altimetry, which is the only operational observing system that facilitates continuous sampling of ocean dynamics on a global basis. The suitability of satellite altimetry to observe the oceanic mesoscale variability has been demonstrated in numerous investigations, e.g., by Willebrand et al. [1990], who validated Geosat sea surface height (SSH) measurements with drifting buoys and hydrographic data. Global statistical descriptions were obtained, ranging from maps of the rms surface height variability to regional spectral analysis and characterization of typical space and time scales of mesoscale variability [e.g., Le Traon et al., 1990; Stammer, 1992]. These statistical descriptions have in common that they are essentially restricted to the ocean surface. It is only our knowledge of ocean dynamics that may enable us to infer subsurface information from the altimetric data set.

Combining ocean dynamics and large amounts of data is best organized around a numerical circulation model. By assimilating the data into such a model, a vast number of observations can be dynamically extrapolated and interpolated both in space and in time to yield a complete and dynamically consistent description of the ocean. It is evident that a single observation of the sea surface topography will not allow a

\footnotetext{
${ }^{1}$ Now at Groupe de Recherche de Géodésie Spatiale, Centre National d'Etudes Spatiales, Toulouse, France.

Copyright 1996 by the American Geophysical Union.

Paper number 95JC03801.

0148-0227/96/95JC-03801\$09.00
}

unique determination of the deep ocean's state. In fact, there are an infinite number of possible states that would all match the surface observations at a given instant. However, different states will evolve differently in time, eventually leading to distinct dynamic topographies. Hence subsequent altimeter measurements, when combined with some understanding of ocean dynamics, will have some potential for gradually revealing the structure of the deep ocean. Along these lines the assimilation of satellite altimeter data becomes a very tempting prospect to globally monitor the state and, of course, also the potential changes of today's ocean.

So far most of the research on assimilation of altimeter data has involved numerical ocean circulation models with very few active layers [Kindle, 1986; Hurlburt, 1986; Hurlburt et al., 1990; Haines et al., 1993] or quasi-geostrophic dynamics [Holland and Malanotte-Rizzoli; 1989; Robinson et al., 1988, 1989; Verron, 1990; White et al., 1990 a, b, c; Haines, 1991]. A common feature of such simple models is that they do not require large computational resources and hence are most appropriate for developing and testing assimilation concepts. On the other hand, they generally fail to resolve some climatologically important physical processes, as, for example, none of these models has prognostic equations for temperature and salinity.

In many respects, primitive equation models with active thermodynamics can simulate the ocean circulation much more realistically. However, because of their complexity, assimilation of altimeter data into such models is not straightforward and has largely been avoided. An exception is the work by Mellor and Ezer [1991] and Ezer and Mellor [1994], who combine a suboptimal interpolation method with a statistical regression scheme to directly estimate temperature and salinity fields from the satellite-measured surface topography. The use 
of a statistical regression method that directly relates temperature and salinity to the observed sea surface height has, however, the disadvantage that any error in the statistics will directly translate into false estimates of water mass properties. As we will illustrate later in this study, this can eventually introduce completely unrealistic water masses, thereby disturbing any reasonable evolution of the dynamical model. Except for some well-sampled regions like the Gulf Stream region investigated by Ezer and Mellor, in practice, neither the still sparse oceanographic data sets nor present numerical circulation models can provide us with the required reliable statistical coefficients.

In this paper we present an alternative assimilation method that specifically avoids any statistical regression to infer temperature and salinity from sea surface height. Our approach is guided by the notion that the distribution of temperature and salinity on isopycnal surfaces has no direct dynamical effect and hence cannot be observed by altimetry. Consequently, the distribution of temperature and salinity on these surfaces should be conserved during the assimilation step, while the assimilation procedure may well change the position of isopycnals. In this way the assimilation does not interfere with the physical process of formation of water masses and their spreading which occurs predominantly along isopycnal/neutral surfaces.

The new assimilation method is described in detail in the next section. It is subsequently tested in an identical twin perspective before being applied to the eddy-resolving World Ocean Circulation Experiment (WOCE) Community Modeling Effort (CME) model configuration of the North Atlantic Ocean [Bryan and Holland, 1989]. A 1-year assimilation experiment is performed using Geosat altimeter data of the year 1987. The results are discussed with special emphasis placed on the role of conserving water mass properties during the assimilation. For comparison, some results of an approach very similar to the one suggested by Mellor and Ezer [1991] are also shown, clearly indicating that our more careful treatment of temperature and salinity can considerably improve the performance of altimeter data assimilation schemes.

\section{The Method}

The basic concept of essentially all sequential data assimilation methods can be illustrated by

$$
\mathbf{x}^{a}=\mathbf{x}^{f}+\mathbf{K}\left(\mathbf{y}^{\text {obs }}-\mathbf{H} \mathbf{x}^{f}\right),
$$

where $\mathbf{x}$ is the state vector of the numerical ocean circulation model, with indices $f$ and $a$ refering to forecast and analysis, respectively. The operator $\mathbf{K}$, which in general will be neither linear nor constant in time, projects (or inverts) the difference between measured variables $y^{\text {obs }}$ and their model forecast counterpart $\mathbf{y}^{f} \equiv \mathbf{H x}^{f}$ onto the model state space. An assimilation cycle then consists of (1) halting the model integration at observation time to obtain a model forecast $x^{f}$ and associated $\mathbf{y}^{f},(2)$ computing the correction $\mathbf{K}\left(\mathbf{y}^{\text {obs }}-\mathbf{H} \mathbf{x}^{f}\right)$ required to adjust the model state to the observations, and (3) restarting the model integration from the updated, or analyzed, state $x^{a}$.

Although one can derive statistical concepts like the Kalman filter that in principle, uniquely determine an optimal operator $\mathbf{K}$ [e.g., Ghil et al., 1981], in practice, one has to cope with limited computer resources that clearly rule out an application of statistically optimal methods to basin-scale eddy-resolving circulation models with typically $O\left(10^{6}\right)$ state variables. Any practical assimilation scheme for such state-of-the-art models can therefore only be an approximation to optimal methods. This also holds for our new approach to assimilate satellite altimeter data, which will be described below.

We have already pointed out that a single sea surface height field does not uniquely determine the state of the ocean. (If it did, one would not have to bother about assimilating altimeter data into numerical circulation models.) When approximating the operator $\mathbf{K}$, one therefore has to be aware of the fact that the inversion of the observed model-data misfit $\left(\mathbf{y}^{\text {obs }}-\mathbf{H x}^{f}\right)$ for a model state vector $x$ is not always well conditioned. Particular care has to be taken with respect to such subspaces of the state space which are not well resolved by the inversion, as these subspaces may be very sensitive to small inaccuracies, either introduced by measurement errors, by incorrect statistical assumptions, or by approximations to the operator $\mathbf{K}$. Quite similar to the "truncated solution" of the singular value decomposition often used in inverse modeling [Wunsch, 1978], it is generally advisable to restrict the inversion to the wellresolved modes of the system under consideration and to exploit additional information to determine an element of the null space.

With respect to the assimilation of satellite altimeter data into primitive equation models we argue that such a null space indeed exists: Disregarding weak nonlinearities in the thermodynamic state equation, there is no way to determine the distribution of temperature and salinity on isopycnal surfaces from altimetry. Previous investigations using quasi-geostrophic ocean models [e.g., Haines, 1991] and even a linearized primitive-equation model [Fukumori et al., 1993] have on the other hand shown that altimeter data can constrain both current and density fields in the ocean interior. As far as linear ocean models are concerned, these findings can be further supported by the theoretical concept of observability [Oschlies, 1994].

On the basis of the above considerations we suggest decomposing $\mathbf{K}$ into three distinct operations to be applied successively: A first operator, $\mathbf{A}$, is used to project the observed model-data SSH misfit onto dynamically consistent corrections to the velocity and density fields (i.e., the fields observable by altimetry) of the model forecast. Here, geostrophy will serve as an appropriate dynamical consistency criterion that keeps the analyzed model state close to the slow (quasi-geostrophic) manifold and avoids strong excitation of gravity waves. The second operator, $\mathbf{B}$, is a weighting matrix that accounts for the relative accuracies of observations, model forecast, and approximations introduced by the operator $\mathbf{A}$. To complete the projection of the observed model-data misfit onto state space, one finally has to determine an element of the nullspace. The function of operator $\mathbf{C}$ is to partition the weighted density increments computed by $\mathbf{B} \cdot \mathbf{A}$ into increments of temperature and salinity. Equation (1) may then be rewritten as

$$
\mathbf{x}^{a}=\mathbf{x}^{f}+\mathbf{C} \cdot \mathbf{B} \cdot \mathbf{A}\left(\mathbf{y}^{\text {obs }}-\mathbf{H} \mathbf{x}^{f}\right),
$$

which is illustrated in form of a flowchart in Figure 1. The operations denoted by $\mathbf{A}, \mathbf{B}$, and $\mathbf{C}$ will be described in the following three subsections.

\subsection{Operator A: Finding a Dynamically Consistent Set of Correction Terms}

Most primitive equation models of the general circulation in use today do not treat sea surface height (SSH) as a prognostic 


$$
\mathcal{A} \cdot\left(\mathrm{y}^{\mathrm{obs}}-\mathcal{H} \mathrm{x}^{J}\right)
$$

$\Downarrow$

$$
\text { B. }\left(\begin{array}{c}
\Delta u \\
\Delta v \\
\Delta \rho
\end{array}\right)=\left(\begin{array}{lll}
\mu_{u} & & 0 \\
& \mu_{v} & \\
0 & & \mu_{\rho}
\end{array}\right)\left(\begin{array}{c}
\Delta u \\
\Delta v \\
\Delta \rho
\end{array}\right)
$$

$\Downarrow$

$$
\text { c. }\left(\begin{array}{l}
\mu_{u} \Delta u \\
\mu_{v} \Delta v \\
\mu_{p} \Delta \rho
\end{array}\right)=\left(\begin{array}{lll}
1 & & 0 \\
& 1 & \\
0 & & c
\end{array}\right)\left(\begin{array}{l}
\mu_{u} \Delta u \\
\mu_{v} \Delta v \\
\mu_{p} \Delta \rho
\end{array}\right)
$$

$\Downarrow$

$$
\mathbf{x}^{a}=\mathbf{x}^{J}+\left(\begin{array}{c}
\mu_{u} \Delta u \\
\mu_{v} \Delta v \\
\delta T\left(\mu_{p} \Delta \rho, \mathbf{x}^{f}\right) \\
\delta S\left(\mu_{p} \Delta \rho, \mathbf{x}^{f}\right)
\end{array}\right)
$$

Figure 1. Flowchart of the assimilation algorithm as presented by equation (2). For the details we refer to sections 2.1 to 2.3 .

variable but employ the rigid-lid approximation to filter out fast external gravity waves. Although it is often stated that free-surface models would greatly simplify the assimilation of satellite altimeter data, we do not think that there is much difference between these two model classes with respect to altimeter data assimilation. This is because of the very close adherence of meso- and large-scale motions to geostrophy found practically everywhere in the ocean except for a narrow region along the equator. Hence there is an almost one to one correspondence between geostrophic surface currents and sea surface height, which makes it easy to transfer any assimilation concept originally developed for a free-surface model to a model version with a rigid lid and vice versa. It is therefore no serious restriction when we present our new assimilation method for a rigid-lid model. Note particularly that simply nudging the sea surface height of a free-surface model alone can have severe drawbacks: Although gravity waves would in principle quickly (on a timescale $f^{-1}$ ) adjust the ocean interior to changes in the surface height, this mechanism is not expected to work very well in numerical ocean circulation models that do not properly resolve all the required gravity wave modes. We suppose that as far as present primitive-equation models are concerned (and especially those with a reasonably fine vertical resolution), the efficiency of any altimeter data assimilation scheme can be considerably improved by exploiting the a priori information that the ocean's evolution closely follows the slow (quasi-geostrophic) manifold. This immediately implies that, no matter whether the primitive-equation model has a free surface or a rigid lid, the assimilation scheme itself should actively extrapolate the surface information into the model ocean interior.

Owing to uncertainties in present geoid models, altimetry cannot yet be used to extract the temporal mean SSH on the mesoscale. Only observations $y^{\text {obs }}$ of temporal anomalies of the sea surface elevation, $\delta \eta^{\text {obs }}$, can be deduced from the data with sufficient accuracy. Accordingly, the operator $\mathbf{H}$ maps the state vector of the model forecast, $\boldsymbol{x}^{f}$, onto a corresponding map of SSH anomalies, $\delta \eta^{f}$, defined relative to the climatological mean sea surface that, because of a lack of alternatives, is presently taken from the model.

In order to reduce the computational load we shall separate horizontal, temporal, and vertical correlations in the ocean. Horizontal and temporal correlations will be exploited prior to the assimilation itself by a mapping algorithm applied to the tracked altimeter data (section 4) which produces objectively interpolated maps of $\delta \eta^{\text {obs }}$ (and also of the expected error variance to be taken into account by operator B) on the model grid. All that is left to the actual assimilation routine is to extrapolate the information provided by the SSH maps in the vertical.

Having available maps of the altimetric SSH residuals, it is then straightforward to compute the model-data misfit in the geostrophic surface velocities,

$$
\Delta \mathbf{u}_{g}=\frac{g}{f} \hat{\mathbf{z}} \times \nabla\left(\delta \eta^{\text {obs }}-\delta \eta^{f}\right),
$$

where $\hat{\mathbf{z}}$ is a unit vector pointing upward, $f$ is the Coriolis parameter, and $g$ is the acceleration due to gravity. This misfit can immediately be used to update the surface velocity of the model forecast. Note that the ageostrophic Ekman part of the surface currents, which cannot be observed by altimetry (but is well simulated by the model), will not be affected by the update. On the other hand, the above relation neglects ageostrophic gradient wind contributions to the model-data misfit, which can for example be important in intense Gulf Stream rings that are, however, not properly resolved in the present $1 / 3^{\circ}$ model resolution. After all, (3) will not allow application of our assimilation method close to the equator.

As pointed out above, it is reasonable to look for some vertical projection of the surface velocity misfit, $\Delta \mathbf{u}_{g}$, into the ocean interior and to adjust the deeper model levels as well. One simple way to relate velocities, $\mathbf{u}$, at given depth $z$ to the geostrophic part of the surface currents, $\mathbf{u}_{g}$, is a statistical linear regression method. For each individual column of model grid points we define the vertical regression coefficients for the zonal and meridional velocity components, $u$ and $v$, respectively, by

$$
R_{u}=\frac{\left\langle\delta u \delta u_{g}\right\rangle}{\left\langle\left(\delta u_{g}\right)^{2}\right\rangle}
$$

and

$$
R_{v}=\frac{\left\langle\delta v \delta v_{g}\right\rangle}{\left\langle\left(\delta v_{g}\right)^{2}\right\rangle}
$$

where $\delta u=u-\langle u\rangle$ denotes the actual deviation of the zonal velocity component $u$ from its climatological mean $\langle u\rangle$ which, again, is provided by the model. Assuming that any deviation of the model from the observations has on average the same vertical profile as typical fluctuations in the model's velocity field, one can then also estimate a pseudo velocity misfit $\Delta \mathbf{u} \equiv$ $\Delta(u, v)$ at any depth level by the linear regression

$$
\Delta u=R_{u} \Delta u_{g} \text { and } \Delta v=R_{v} \Delta v_{g}
$$

In this way any observed model-data misfit in the geostrophic surface velocity, $\Delta \mathbf{u}_{g}$, is projected onto a complete threedimensional field of estimated pseudo velocity misfits $\Delta \mathbf{u}$. Figure 2 shows vertical profiles of $R_{u}$ for all model grid points 


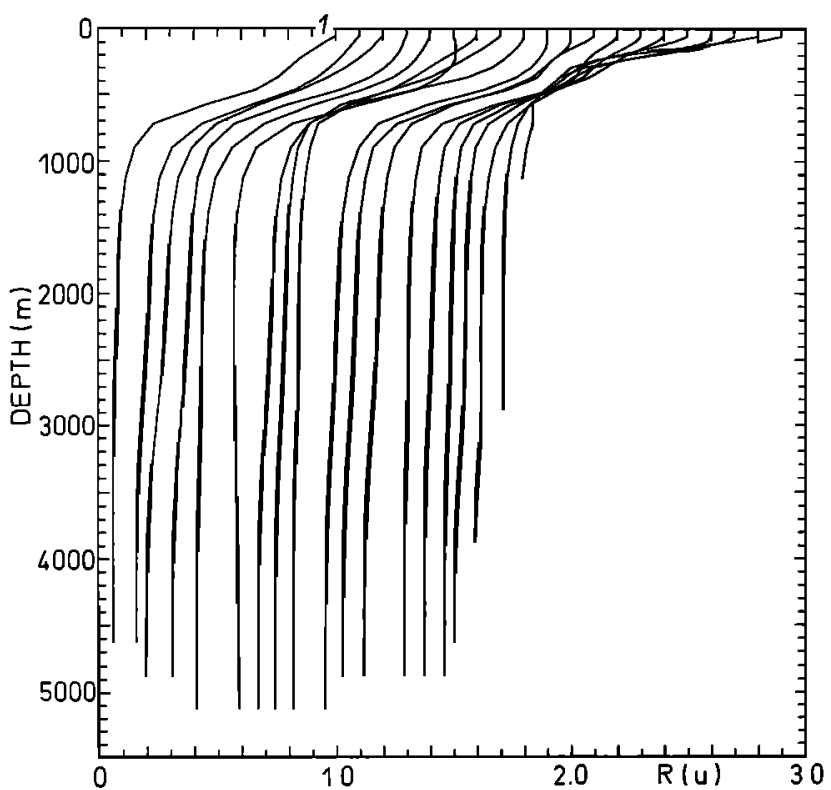

Figure 2. Profiles of the regression coefficients $R_{u}$ derived from a 3-year model climatology run. Profiles are shown for all model grid points along a section crossing the Gulf Stream from $60^{\circ} \mathrm{W}, 36^{\circ} \mathrm{N}$ to $50^{\circ} \mathrm{W}, 43^{\circ} \mathrm{N}$, with an offset of 0.1 each.

along a section crossing the Gulf Stream from $60^{\circ} \mathrm{W}, 36^{\circ} \mathrm{N}$ to $50^{\circ} \mathrm{W}, 43^{\circ} \mathrm{N}$. (The position of this section is indicated in Figure 9.) The regression profiles consistently show that the region of strongest vertical shear is associated with the main thermocline, with only small horizontal variations. (See Figure 10c for an instantaneous temperature field of the model climatology run along this section.)

From the theory of geostrophic adjustment it is known that on scales larger than the Rossby radius of deformation, i.e., on the scales of interest in a general circulation model, the velocity field adjusts itself to the density field. This implies that a corresponding correction $\Delta \rho$, that dynamically balances the above estimated velocity corrections $\Delta \mathbf{u}$, should be applied to the model's density field as well. Such a $\Delta \rho$ may be found as a solution of the following inverse problem: By combining hydrostatic and geostrophic assumptions, the thermal wind equation relates vertical shear in the horizontal velocity field to horizontal gradients of the in situ density field. When applied to the zonal and meridional components of estimated velocity corrections, $\Delta u$ and $\Delta v$, this results in two equations for the single unknown $\Delta \rho$,

$$
\frac{g}{f \rho_{0}} \frac{\partial \Delta \rho}{\partial y}=\frac{\partial \Delta u}{\partial z}
$$

and

$$
\frac{g}{f \rho_{0}} \frac{\partial \Delta \rho}{\partial x}=-\frac{\partial \Delta v}{\partial z}
$$

where $\rho_{0}=\rho_{0}(z)$ refers to the background density profile. Using (6) and (3) to substitute for the velocity increments, one obtains

$$
\frac{\partial \Delta \rho}{\partial y}=-\rho_{0} \frac{\partial R_{u}}{\partial z} \frac{\partial}{\partial y}\left[\delta \eta^{\mathrm{obs}}-\delta \eta^{f}\right]
$$

and

$$
\frac{\partial \Delta \rho}{\partial x}=-\rho_{0} \frac{\partial R_{v}}{\partial z} \frac{\partial}{\partial x}\left[\delta \eta^{\mathrm{obs}}-\delta \eta^{f}\right] .
$$

Because the $z$ derivatives of the statistically derived regression coefficients are neither the same for $R_{u}$ and $R_{v}$ nor horizontally homogeneous, the overdetermined inverse problem given by (9) and (10) does not provide a consistent solution for $\Delta \rho$. Only approximate solutions can be determined.

We proceed by assuming the vertical regression coefficients $R_{u}$ and $R_{v}$ to be horizontally homogeneous. A comparison of the section of regression profiles shown in Figure 2 with corresponding $\mathrm{SSH}$ fields (Figure 9) reveals that at least on the scale of individual eddies, the regression coefficients can indeed to a good approximation be treated as horizontally homogeneous quantities. Moreover, it is likely that the errors due to imperfect model statistics are more critical than neglecting small horizontal variations in these still uncertain coefficients. Giving both of the above relations the same weight, in a least squares sense the optimal $\Delta \rho$ then becomes

$$
\Delta \rho=-\rho_{0} \frac{\partial}{\partial z}\left(\frac{R_{u}+R_{v}}{2}\right)\left[\delta \eta^{\text {obs }}-\delta \eta^{f}\right] .
$$

The integration constants have been set to zero because for a perfect forecast of the sea surface elevation (i.e., $\delta \eta^{f}=\delta \eta^{\text {obs }}$ ) the density field should not be changed (i.e., $\Delta \rho=0$ ).

It is relevant in practice that the above relationship between density changes and surface height anomalies is a local one and hence can be evaluated for each water column individually. Besides having the advantage of sufficiently low computational cost, a local relationship also allows straightforward application to data sets like maps of tracked altimeter measurements with their intrinsic spatially inhomogeneous data coverage and error structure. In particular, the density increment $\Delta \rho$ is related to the scalar field $\delta \eta$ itself, i.e., no horizontal derivatives of the surface height measurements are required at this point. (Spatial derivatives of the (mapped) data were, however, used to compute the changes in the velocity field in (3).)

\subsection{Operator B: Applying Weighting Coefficients}

Together with the statistically estimated velocity deviations $\Delta u$ and $\Delta v$, the density increment $\Delta \rho$ provides an approximately balanced and hence dynamically self-consistent estimate for the correction to the forecast state $\mathrm{x}^{f}$ in $\{u, v, \rho\}$ space. In order to use these estimated correction terms to update the model forecast (equation (2)), their reliability relative to that of the model forecast should be taken into account in form of some weighting matrix $\mathbf{B}$.

In principle, one could determine a statistically optimal weighting matrix $\mathbf{B}$ by minimizing the expected error covariance of the updated state $x^{a}$. This procedure would eventually result in the product $\mathbf{B} \cdot \mathbf{A}$ becoming similar to the so-called gain matrix of the Kalman filter (in $\{u, v, \rho\}$ space), with the difference that we have explicitly tied the geostrophic balance condition into operator $\mathbf{A}$, whereas the Kalman gain matrix would reflect geostrophy implicitly via the statistics of the ocean. Recalling the figure of $O\left(10^{7}\right)$ state variables, it is evident that neither computing nor storing such a matrix $B$ would be feasible for an eddy-resolving ocean circulation model as considered in this study.

To cope with the limited computer resources, we shall therefore choose a diagonal matrix $\mathbf{B}$, its elements being weighting coefficients $\mu_{u}, \mu_{y}$, and $\mu_{\rho}$ (to be defined at each grid point). 
Beginning with the zonal velocity field and inserting the corrections $\Delta u$ into (2), we then obtain a scalar equation for each component of the updated velocity field

$$
u^{a}=u^{f}+\mu_{u} \Delta u=u^{f}+\mu_{u} R_{u}\left(u_{g}^{\mathrm{obs}}-u_{g}^{f}\right)
$$

with $u_{g}^{\text {obs }}-u_{g}^{f}=\Delta u_{g}$ given by (3). (The operator $\mathbf{C}$ does not affect the velocity components and hence does not appear in the above equation.)

Neglecting any correlations between errors of different quantities, one can then derive a set of weighting coefficients $\mu_{u}$ (one for each velocity variable of the model) that minimize the expected error variance of the updated velocity components $u^{a}$. As outlined in the appendix, the resulting expression for $\mu_{u}$ is a function of the relative errors of model forecast and observations and also of the error introduced by the simple vertical projection scheme represented by the linear regression coefficient $R_{u}$ (equation (6)). While one can readily obtain reasonable estimates for the expected errors of the (mapped) altimeter data (see section 4), as well as for the error introduced by the vertical extrapolation scheme, it remains a major difficulty to determine the forecast error of the assimilation model. Clearly, the forecast error depends on the length of the forecast period. Although the time interval between successive assimilation steps is only 5 days, the frequency with which relevant information is mapped onto a particular grid point will still be governed by the satellite's repeat period ( 17 days in the case of Geosat).

For simplicity, it was finally decided to approximate the forecast error variance of any model variable (of the assimilation run) as a time-independent constant, set equal to the process variance of the respective variable (of the model with no data assimilated). Although at first sight this relatively large error estimate seems to be a rather pessimistic assessment of the model's forecast ability, it is actually quite optimistic in regions like the eastern North Atlantic, where the model (with no data assimilated) underestimates the surface height variability by up to a factor of 4 [Stammer and Böning, 1992]. To the extent that the assimilation of Geosat data is able to increase the model's SSH variability (see section 5 for an analysis), the estimated forecast error will be even smaller than the variance of the assimilation run.

Employing these simplifying assumptions one can then derive the following expression for the weighting coefficients used to update the velocity components (see appendix for a more detailed discussion):

$$
\mu_{u}=C_{u, u_{g}}^{2}\left(1-r_{\eta}\right)^{2}
$$

where the squared correlation coefficient

$$
C_{u, u_{g}}^{2}=\frac{\left\langle\delta u \delta u_{g}\right\rangle^{2}}{\left\langle\left(\delta u_{g}\right)^{2}\right\rangle\left\langle(\delta u)^{2}\right\rangle}=R_{u}^{2} \frac{\left\langle\left(\delta u_{g}\right)^{2}\right\rangle}{\left\langle(\delta u)^{2}\right\rangle}
$$

accounts for the accuracy of the linear regression scheme used for vertical extrapolation, and $r_{\eta} \in[0,1]$ is the expected error variance of the local surface height value, normalized by the variance of the SSH field. Like the regression coefficients $R_{u}$ the correlation coefficients are taken from the model climatology, while $r_{\eta}$ is provided by the SSH mapping routine (section 4). Note that both inaccurate surface height observations (i.e., $r_{\eta}>0$ ) as well as imperfect vertical correlations (i.e., $C_{u, u_{g}}^{2}<1$ ) will reduce the weight of the estimated velocity correction $\Delta u$. If on the other hand observations and vertical projection were perfect (i.e., $\mu_{u}=1$ ), the model forecast $u^{f}$ would be completely discarded and (12) would yield $u^{a}=R_{u} u^{\text {obs }}$.

To give an analogous expression for the remaining weighting coefficient $\mu_{\rho}$, we note that via (11) the density increment $\Delta \rho$ is directly coupled to the vertical derivative of the regression coefficients $R_{u}$ and $R_{v}$. For this reason, the relative error in the vertical shear of these regression profiles has been set to the minimum accuracy of the coefficients that contribute to the (discrete) derivative. The explicit form for the weighting parameters $\mu_{\rho}$ then becomes

$$
\mu_{\rho}=\min _{\substack{u_{\text {up }}, u_{\text {low }} \\ v_{\text {up, }} \text { low }_{\text {low }}}}\left(C_{\ldots, u_{q}}^{2}\right)\left(1-r_{\eta}\right)^{2},
$$

where the subscripts up and low denote the vertical levels used for computing the individual $z$ derivative in (11). As for (13), $C^{2} \ldots, u$ is the corresponding squared correlation with the surface velocity, and $r_{\eta}$ is the estimated relative error variance of the mapped altimeter data.

It remains to add the set of weighted increments $\mu_{u} \Delta u$, $\mu_{v} \Delta v$, and $\mu_{\rho} \Delta \rho$ to the forecast state vector $\mathrm{x}^{f}$ in order to obtain the analyzed state $x^{a}$. Only for such models that treat temperature and salinity independently and hence do not carry density itself as a prognostic state variable is it necessary to partition the computed correction to the density field of the model forecast into corresponding changes of temperature and salinity. This will be the function of operator $\mathbf{C}$.

\subsection{Operator C: Partitioning Density Into Temperature and Salinity Increments}

In many primitive equation models, temperature and salinity, rather than density itself, are the prognostic variables of the model. In that case, $\mu(\rho) \Delta \rho$ has to be partitioned into increments of temperature and salinity. It is evident that for a particular density there is no unique solution to this inverse problem as long as temperature and salinity are treated as independent variables. However, in the ocean these quantities are not really independent but are closely tied to individual water masses. Once a water mass has been formed and the water is no longer in direct contact with the atmosphere, its potential temperature and salinity, and hence potential density, can for many purposes be considered as fixed. Ocean eddies can to a good approximation be regarded as adiabatic features. In this respect it is only the action of the surface conditions in the water mass formation area that simultaneously determine, and thereby interrelate, temperature and salinity.

This underlines our previous conclusion that there is no reason to change the distribution of (potential) temperature and salinity on isopycnal surfaces when assimilating altimeter data. It is the conservative aspect of water mass properties which immediately provides us with the additional constraint required for a unique inversion of $\mu(\rho) \Delta \rho$ for changes of the temperature and salinity forecast fields.

For a level model, as considered in this study, the suggested algorithm first computes the analyzed (in situ) density $\rho_{k}^{a}=$ $\rho_{k}^{f}+\mu\left(\rho_{k}\right) \Delta \rho_{k}$ at each depth level $k$. Subsequently, it searches in the local water column of the forecast state for a water parcel (defined by a $\boldsymbol{\theta}-\boldsymbol{S}$ point) that, when moved adiabatically to the depth level under consideration, produces the new density $\rho_{k}^{a}$. In case of a potentially unstable stratification, there may be more than one $\theta-S$ point that satisfy this criterion, whereupon the algorithm always selects the water that 
requires the minimum vertical displacement. As long as the density change does not lead to the introduction of new potential densities (with the reference pressure of depth level $k$ ) not already present in the original water column, this procedure uniquely determines the analyzed temperature and salinity fields. When, on the other hand, the analyzed density exceeds the range of potential densities of the model forecast, no vertically displaced water parcel of the forecast state can acquire the density $\rho_{k}^{a}$. In such cases, which are most likely to occur when light water is introduced at the top, some extrapolation of the original $\theta-S$ relation toward lower (or greater) densities has to be provided. A simple linear extrapolation of the temperature and salinity differences between adjacent depth levels is not always well behaved when large vertical gradients in temperature and salinity counteract, which turns out to be a particular problem in the seasonal thermocline. Therefore temperature and salinity are additionally constrained to remain within $3^{\circ} \mathrm{C}$ and 0.5 psu of the model forecast values.

\section{An Identical Twin Experiment}

An appropriate criterion for rating the success of an assimilation experiment is its ability to drive the model state closer toward reality. Since the state of the real ocean is far from being known accurately, we resort for this question to identical twin experiments. They allow objective measurement of the convergence of the assimilation run by computing the difference between state vectors of the assimilation and control run. For computational economy the simplified box model configuration developed by Cox [1985] with rough bottom topography introduced by Böning [1989] was used for testing our new assimilation scheme. The model is based on essentially the same numerical code as the CME model, which is subsequently used for assimilating Geosat data. The only change in the physics is a simplified state equation: There is no salt in the model, and density $\rho$ is a linear function of the single state variable potential temperature $T$ only; hence this test does not involve operator $\mathbf{C}$. The model is set up for a simplified basin of $60^{\circ}$ longitudinal width, extending from the equator to $65^{\circ} \mathrm{N}$. There are 21 levels in the vertical and the horizontal resolution is $1 / 3^{\circ} \times 2 / 5^{\circ}$.

The model years 30 to 32 are taken as climatology. Complete fields of the diagnostically calculated surface pressure as well as the corresponding three-dimensional fields of velocity components and temperature are stored twice a day for the model year 30 . In the identical twin experiments these data from the so-called control run serve as substitute for the real world. The surface pressure maps are subsequently assimilated into the assimilation run that starts from different initial conditions at the beginning of model year 31 . An objective criterion for the convergence of the assimilation process can then be obtained by computing the rms difference between the fields of the assimilation run and those stored from the control run.

The temporal evolution of these rms differences is displayed in Figure 3 for the horizontal velocity field at selected depth levels as well as for temperature. The corresponding curves for the reference run with no data assimilated are also shown. It is evident that the assimilation of surface height data can considerably improve the model's representation of the ocean interior. After 82 days, i.e., 16 assimilation cycles, the errors in the surface (at $17.5 \mathrm{~m}$ ) velocities have been reduced to $25 \%$ and those of the fifth model level (at $174 \mathrm{~m}$ ) to $33 \%$ of the corresponding values of the reference run. The still decreasing rms error in the model temperature has reduced to $47 \%$ and that of horizontal velocity at $1800 \mathrm{~m}$ to $60 \%$. Note that the errors in the near-surface variables apparently have almost reached their asymptotic values after very few assimilation cycles, while convergence of the ocean interior is much slower. This clearly indicates the important role of the numerical model in successively absorbing the assimilated information and carrying it forward in time.

Overall, the assimilation procedure leads to significant and encouraging convergence of all model variables. The observed rms error reduction is close to (though slightly better than) the values reported by Cooper and Haines [1996], who performed identical twin experiments using exactly the same circulation model with a different assimilation scheme that is based on conservation of potential vorticity. Nevertheless, we wish to emphasize that because the simulated observations are dynamically and statistically consistent with the assimilation model, the results of such twin experiments tend to be overoptimistic with respect to applications to real data. A fair assessment of an assimilation method's performance will eventually have to involve its application to real data.

\section{Data Preprocessing}

The altimeter data used in this study are from the Exact Repeat Mission (ERM) of the U.S. Navy's Geodetic Satellite (Geosat). The data are available approximately every $7 \mathrm{~km}$ along each of the 244 ground tracks produced by the 17-day repeat orbit. A collinear analysis method as described in detail by Willebrand et al. [1990] was used to determine SSH residuals relative to a 2-year reference mean. In order to separate the horizontal, temporal, and vertical extrapolation problem, it was decided to map the tracked SSH residuals onto the model grid prior to the actual assimilation. A time series of quasisynoptic maps, covering the entire model domain, was produced using a linear space-time objective analysis technique [Bretherton et al., 1976]. To reduce the computational burden of interpolating $O\left(10^{5}\right)$ Geosat observations onto some $5 \times$ $10^{4}$ model surface grid points, it was decided to use a suboptimal method. The algorithm chosen is described by $\mathrm{De}$ Mey and Ménard [1989]. It greatly reduces the number of data points for the objective analysis by considering only statistically independent data within a chosen influence radius (typically $400 \mathrm{~km}$ and 30 days). Like any objective analysis algorithm it nevertheless requires some a priori information in the form of a correlation function.

Stammer and Böning [1992] showed that for the North Atlantic the spatial autocorrelation functions, averaged over $10^{\circ}$ by $10^{\circ}$ boxes, of the Geosat SSH residuals are not significantly different for ascending and descending tracks. They further found generally good agreement between these autocorrelation functions and the analytic functions estimated from the local POLYMODE [De Mey and Robinson, 1987] and TOURBILLON [Arhan and Colin de Verdière, 1985] experiments (Figure 4a). On the basis of this evidence, in the present study the same analytic isotropic form of the spatial autocorrelation function as for the POLYMODE experiment was used for the mapping:

$$
C(r)=\left[1+a r-\frac{1}{3}(a r)^{3}\right] e^{-a r}
$$

where $a=2.1038 / L_{0}$ and $L_{0}$ is the lag of the first zero crossing. As further shown by Stammer and Böning [1992], $L_{0}$ 

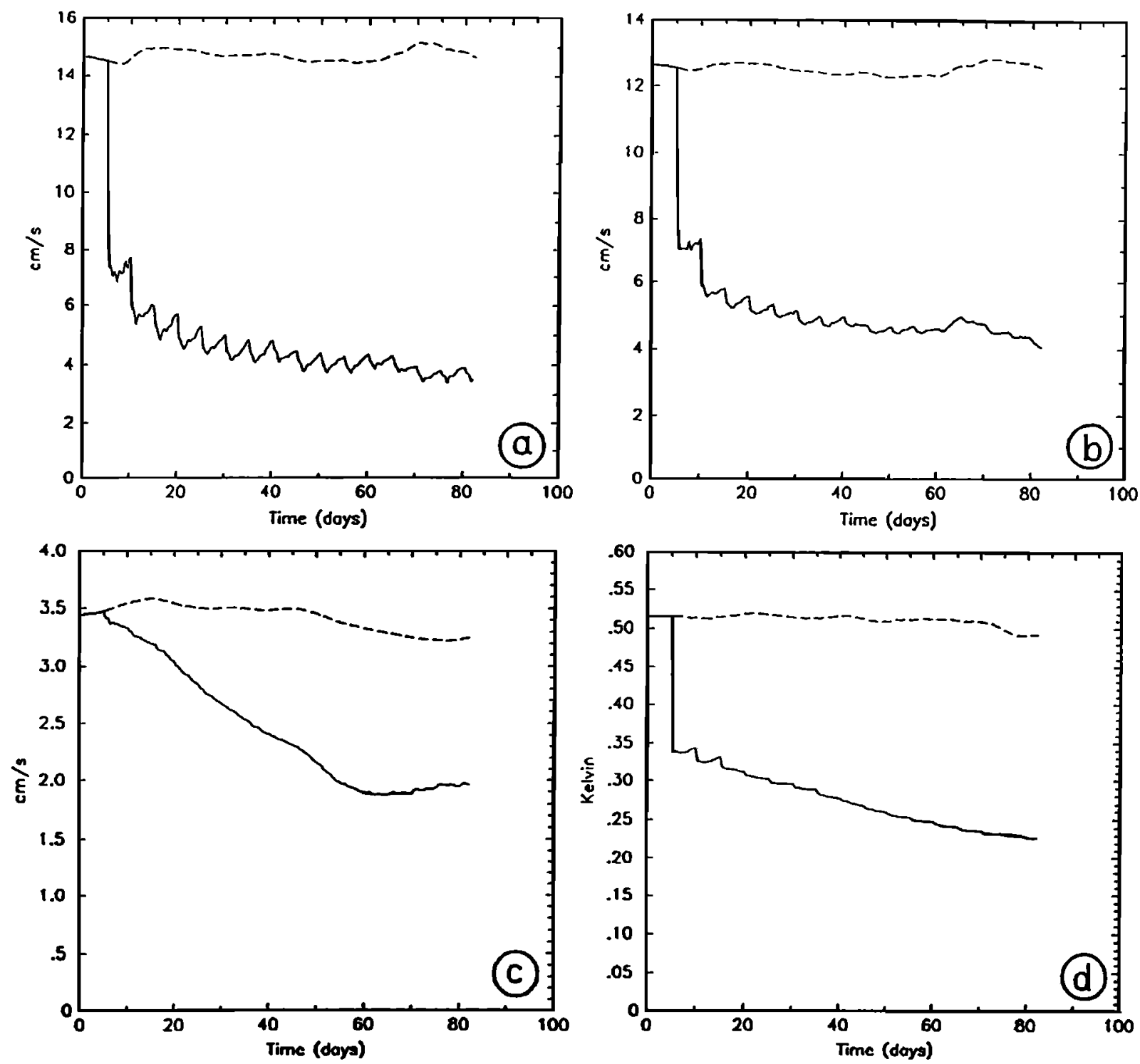

Figure 3. Temporal evolution of rms differences between control and assimilation run: (a) velocity differences at $17.5 \mathrm{~m}$, (b) at $174 \mathrm{~m}$, and (c) at $1800 \mathrm{~m}$. (d) Temperature rms differences integrated over the entire basin. The dashed curves represent the reference run with no data assimilated; the solid curves refer to the assimilation experiment.

decreases rather smoothly from $255 \mathrm{~km}$ at the equator to 90 $\mathrm{km}$ at $60^{\circ} \mathrm{N}$ with only little zonal variations. An analytic model for the lag of the first zero crossing $L_{0}$ was therefore fitted to the zonal averages of the Geosat values (see Figure $4 \mathrm{~b}$ ):

$$
L_{0}(\lambda, \varphi) \equiv L_{0}(\varphi)=50 \mathrm{~km}+205 \mathrm{~km} \frac{\varphi_{0}^{2}}{\varphi^{2}+\varphi_{0}^{2}}
$$

with $\varphi_{0}=30^{\circ}$. The spatial autocorrelation function modeled by (17) was then multiplied by a stationary Gaussian decay, $D(t)=\exp \left(-t^{2} / T^{2}\right)$, with $T=10$ days. With regard to an instrumental noise level of about $3.5 \mathrm{~cm}$ rms [Sailor and Le Schack, 1987], the Geosat data exhibit a relatively low signal to noise ratio for large parts of the North Atlantic Ocean [e.g., Stammer et al., 1991]. We therefore finally assumed a white noise level of $30 \%$ of the local process variance (within the chosen influence radius).

The mapping routine was then applied to the Geosat SSH residuals resulting from the collinear analysis. A sequence of maps covering the year 1987 at 5-day intervals was produced. Together with the mapped SSH field a corresponding map of the estimated relative error variance $r_{\eta}=\sigma^{2}\left(\eta^{\text {obs }}\right) / \operatorname{Var}\left(\eta^{\mathrm{obs}}\right)$, required to set up the weighting matrix $\mathbf{B}$ (section 2.2), was obtained. As an example, Figure 5 shows a $10^{\circ} \times 10^{\circ}$ region of estimated surface height (Figure $5 \mathrm{a}$ ) together with the estimated relative error variance (Figure 5b).

\section{Assimilation Experiment}

In the following, the new assimilation method described above is applied to the Community Modeling Effort (CME) model configuration originally developed by Bryan and $\mathrm{Hol}$ land [1989]. The model is based on the primitive-equation ocean circulation model described by Bryan [1969] and Cox [1984]. It covers the entire Atlantic Ocean between $15^{\circ} \mathrm{S}$ and 

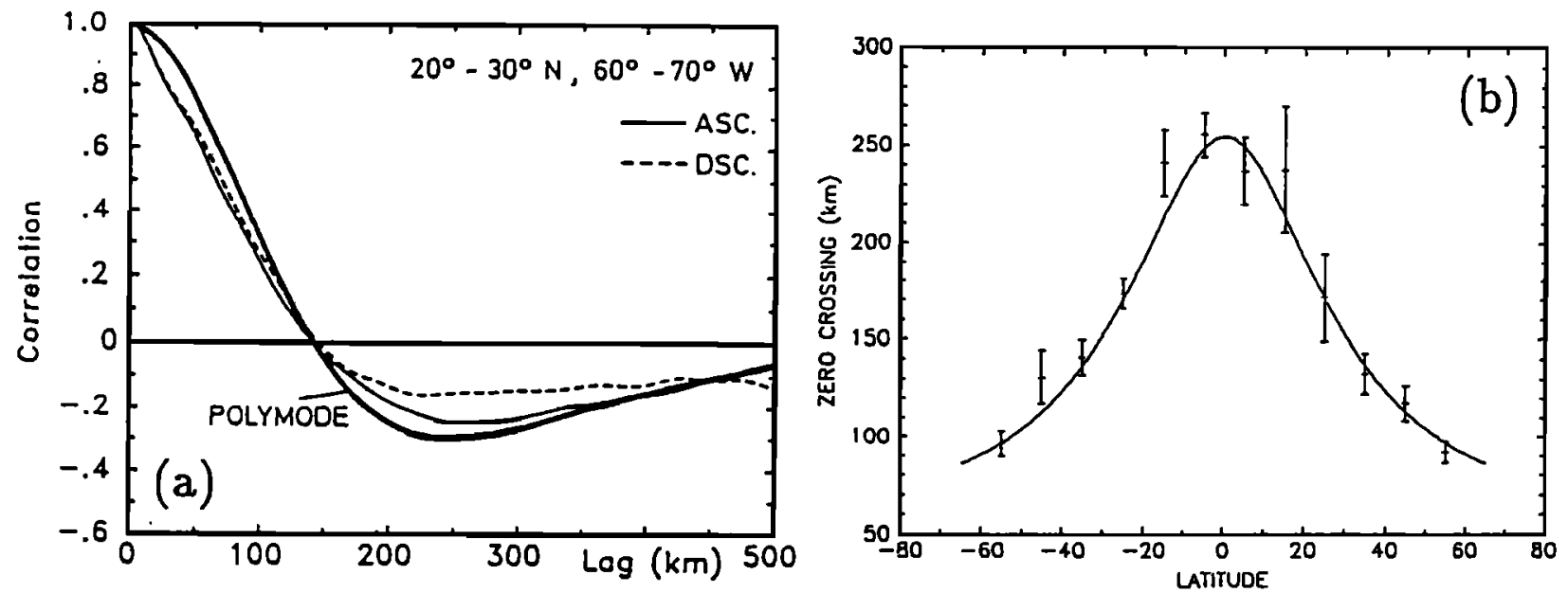

Figure 4. (a) Geosat mean autocorrelation function from ascending (solid line) and descending (dashed line) tracks in the $10^{\circ}$ by $10^{\circ}$ box $20^{\circ}-30^{\circ} \mathrm{N}, 60^{\circ}-70^{\circ} \mathrm{W}$. Included is the analytic autocorrelation function (17) representing typical POLYMODE sea surface stream function statistics [De Mey and Robinson, 1987]. (reprinted with permission from Stammer and Böning [1992].) (b) Zonal averages of the lag of the first zero crossing of the Geosat SSH autocorrelation function (from Stammer and Böning [1992]. Also shown is the analytic fit $L_{0}(\varphi)$ used for the mapping routine.

$65^{\circ} \mathrm{N}$ (Figure 7) and the grid spacing is $1 / 3^{\circ}$ in meridional and $2 / 5^{\circ}$ in zonal direction. In the vertical, 30 levels are used, with a vertical spacing increasing smoothly from $35 \mathrm{~m}$ at the surface to $250 \mathrm{~m}$ below $1000 \mathrm{~m}$. Northern and southern lateral boundaries are closed as is the Strait of Gibraltar, with buffer zones of a width of five grid points at which the temperature and salinity of the water is relaxed to values taken from Levitus [1982]. A simple mixed layer model [after Camp and Elsberry, 1978] computes the depth of vertically uniform temperature and salinity from the vertical flux of kinetic energy in the atmospheric boundary layer.

The model was originally started from rest with initial temperature and salinity fields taken from the Levitus [1982] climatology. The model configuration used in this study is iden- tical to the one described by Böning and Herrmann [1994] as experiment 4 . It is forced with monthly mean wind stresses of Isemer and Hasse [1987] north and of Hellerman and Rosenstein [1983] south of the equator (with a transition zone between $0^{\circ}$ and $5^{\circ} \mathrm{N}$ ). Obviously, this climatological wind forcing will not be fully consistent with the SSH residuals measured by Geosat in 1987, and the assimilation will to some extent have to correct for the imperfect winds. Future experiments are planned to further investigate the role of accurate wind forcing by using synoptic wind stress analyses from the European Center for Medium Range Weather Forecasting. The thermohaline forcing of the model is represented by a relaxation of surface salinity to the monthly mean values of Levitus [1982] and a heat flux given by the linear formulation of $\operatorname{Han}$ [1984]. As men-
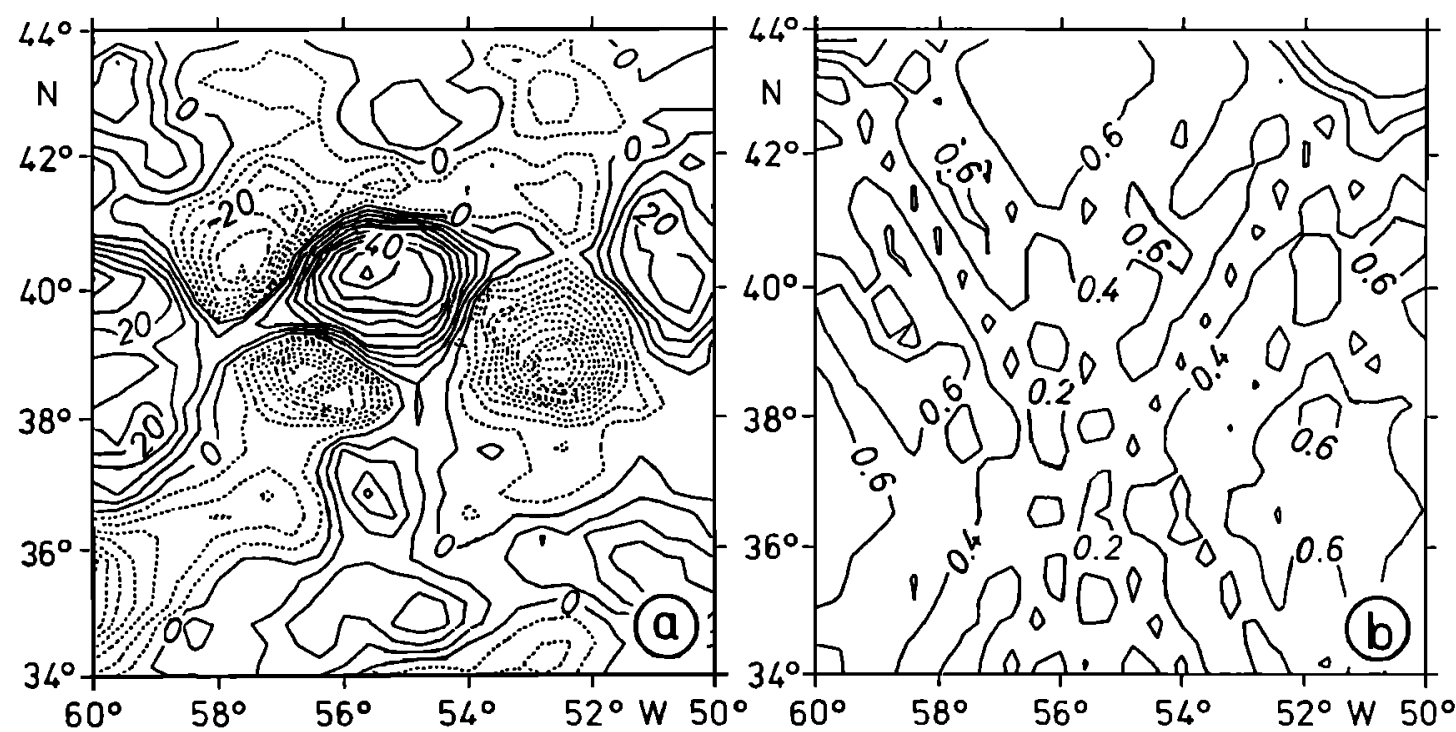

Figure 5. Objectively mapped Geosat data for March 19, 1987. (a) Sea surface height in centimeters; (b) estimated relative error variance. Region and time chosen correspond to that of the subsequent intercomparison with hydrographic data. 
tioned previously, the CME model has a rigid lid. Consequently, surface pressure (within the hydrostatic assumption equivalent to surface height) is not a prognostic variable, but it can be computed diagnostically from the model state [e.g., Semtner, 1986].

Despite its high degree of realism, compared with most other basin-scale eddy-resolving ocean circulation models, the CME configuration of the North Atlantic Ocean still exhibits considerable systematic deficiencies. All the simulations performed so far have shown a rather unrealistic flow pattern in the Gulf Stream separation region, and the representation of mean frontal structures and eddy variability as associated with the North Atlantic Current (NAC) and the Azores Current (AC) is not really satisfactory [Beckmann et al., 1994a, b]. Quite generally, the intensity of mesoscale variability is found to be considerably underestimated [Stammer and Böning, 1992]. Only in the equatorial region a good agreement between SSH variability as simulated by the model and measured by Geosat exists [Didden and Schott, 1992]. Consequently, we expect the largest impact of the assimilation in the subtropical and subpolar regions. To avoid problems that can arise from applying the geostrophic assumption inherent in the assimilation scheme developed close to the equator, it was decided to restrict the assimilation to the region north of $10^{\circ} \mathrm{N}$. A sequence of objectively analyzed maps of Geosat measured SSH anomalies, covering the year 1987 at 5-day intervals, is then assimilated into a 1-year run of the eddy-resolving CME model. The experiment begins at January 1, 1987, and the model is initialized with the restart state of model year 32, which can therefore serve as reference run with no data assimilated.

To obtain a first estimate of the assimilation experiment's performance, rms differences between the SSH maps derived from the Geosat data set and those diagnosed from the numerical model have been computed. (We used the mapped data set because considerable temporal fluctuations in both number and location of valid Geosat measurements dominated rms differences with respect to the tracked data.) Figure 6 shows time series of these rms differences for three different experiments: reference (R) and assimilation experiment (A) as well as a forecast experiment (F) which is initialized with the model state reached by the assimilation run after half a year (at day 182) but subsequently runs in a pure forecast mode with no further data assimilated. As a typical feature of sequential assimilation, the rms error of the assimilation run resembles a sawtooth curve, with the error increasing steadily between successive assimilation steps and being reduced instantaneously at any of such steps.

It is found that by assimilating surface height observations the original model-data difference of the reference run can be reduced by about $35 \%$. Note that a fairly constant difference level is already reached after about 20 days, i.e., four assimilation cycles, or just one Geosat repeat cycle, and it takes only little more time for the model-data differences of the forecast experiment to increase back to values typical for the reference run. At first sight this relatively poor predictive skill seems to indicate only a minor role of the dynamical model for absorbing and carrying forward in time the assimilated observational information. However, the integral quantity of global ms differences does not distinguish between contributions due to errors in the intensity of the eddy field (which we are interested in) and contributions that arise from phase errors (which we are not really interested in). In the forecast experiment the

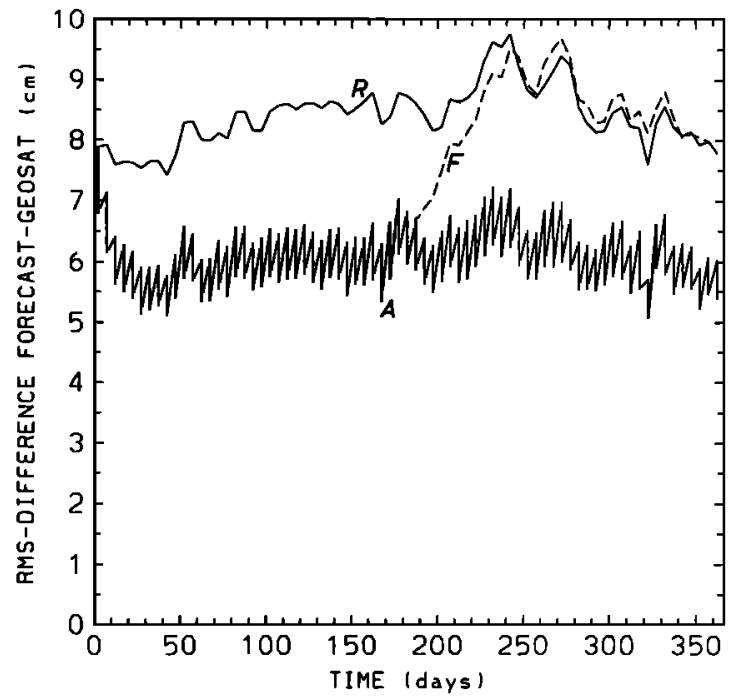

Figure 6. Temporal evolution of the $\mathrm{rms}$ SSH differences between objectively analyzed Geosat maps and model reference run (R), assimilation run (A), and forecast run (F), respectively. All model grid points with estimated Geosat map error variance smaller than 0.6 have been used in the computation of the rms model-data difference.

latter particularly result from imperfections in the model climatology, which serves as reference for the Geosat SSH anomalies and thereby introduces errors in the background advective flow for the eddy field. In fact, the evolution of the rms forecast error (curve F of Figure 6) almost coincides with the corresponding curve for a persistence forecast (not shown).

Next, we shall investigate the effect the assimilation of Geosat data has on the spatial distribution of eddy activity. Figure 7 displays the rms variability of the various surface height fields. The surface variability of the reference run with no data assimilated (Figure 7a) shows maximum values of about $22 \mathrm{~cm}$ rms near $35^{\circ} \mathrm{N}, 70^{\circ} \mathrm{W}$, where the separating Gulf Stream forms a large, unrealistic loop before turning eastward. The region of maximum variability then follows the path of the Gulf Stream and the North Atlantic Current (NAC). The NAC does not properly cross the Mid-Atlantic Ridge (MAR) but instead forms a spurious band of high variability in the Irminger Sea southeast of Cape Farewell. The enhanced variability in the tropical Atlantic is associated with the seasonal cycle of the North Equatorial Counter Current (NECC) and the retroflecting North Brazil Current, which turns toward the NECC during summer. As shown by Schott and Böning [1991], there is good correspondence between CME model results and observational evidence in this region.

Differences in the spatial distribution of the rms surface variability between the original CME model run and the corresponding Geosat maps are most pronounced north of $30^{\circ} \mathrm{N}$. The rms variability inferred from the Geosat data (Figure $7 \mathrm{~b}$ ) is largest in the Gulf Stream extension along $40^{\circ} \mathrm{N}$ between $70^{\circ} \mathrm{W}$ and $40^{\circ} \mathrm{W}$. Farther downstream there are two branches of high variability crossing the MAR, one corresponding to the NAC at about $50^{\circ} \mathrm{N}$, while the other one at $35^{\circ} \mathrm{N}$ is associated with the Azores Current (AC). In most places the variability in the Geosat maps exceeds that of the $\mathrm{CME}$ model, with two notable exceptions: The maxima in the model surface variabil- 

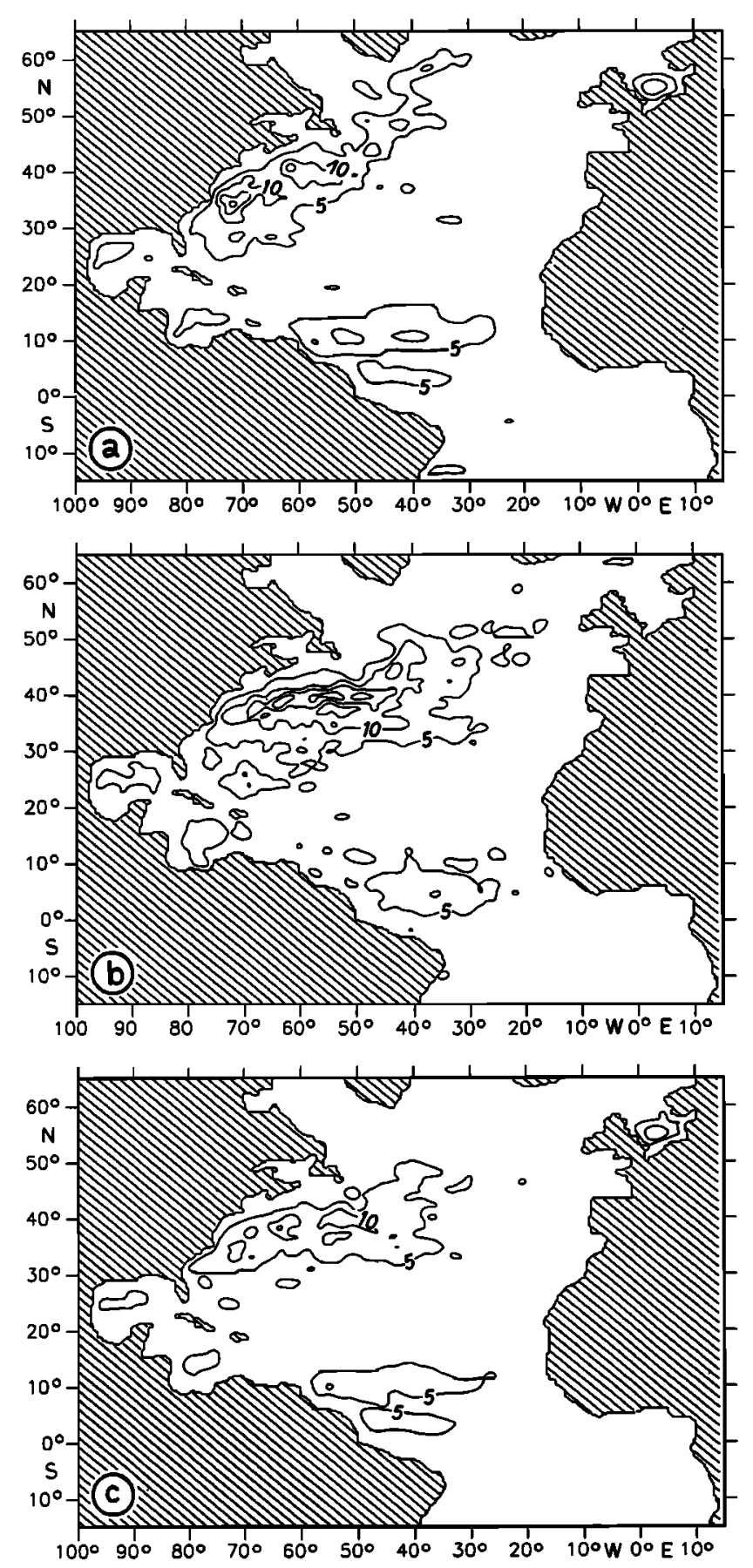

Figure 7. Variability of sea surface height computed from 14 maps separated by intervals of 26 days, for (a) CME model reference run with no data assimilated, (b) Geosat maps that treat all data within a 17-day period as synoptic, and (c) sea surface height variability of the assimilation experiment. Contour interval is $5-\mathrm{cm}$ rms.

ity in the Irminger Sea and also near the Gulf Stream separation are not in agreement with the satellite observations.

It is evident from Figure $7 \mathrm{c}$ that the assimilation experiment with some success reproduces the spatial distribution of the rms surface variability in the Geosat data. Not only the NAC but also the $\mathrm{AC}$ are indicated by regions of intensified variability, penetrating into the eastern basin. Consistent with the
Geosat observations, the position of the highest variability has moved from the Gulf Stream separation region to the Gulf Stream extension. Moreover, the assimilation can apparently suppress the spurious signal in the Irminger Sea. In general, the changes due to the assimilation are encouraging as far as the spatial distribution of surface height variability is concerned, whereas the rms intensity of surface height fluctuations continues to be systematically underestimated.

Wavenumber spectra of the surface height variability in several regions are shown in Figure 8. For a number of $10^{\circ}$ by $10^{\circ}$ boxes annual averages of meridional SSH spectra are computed, treating spectra separated by $2^{\circ}$ zonally and 26 days temporally as independent. To retain consistency with the model output, the Geosat spectra are not computed alongtrack (for reference an along-track spectrum is included in Figure 8c), but instead meridional spectra are derived from maps like the one shown in Figure 9b, also separated by 26 days and $2^{\circ}$ zonally. Hence the shortest wavelength that can be supported by the model grid ( $74 \mathrm{~km}$ meridionally) determines the cutoff wavenumber of these Geosat spectra. From Figure 8 it is obvious that there are considerable differences between the spectral energy densities refering to Geosat data and the CME model with no data assimilated. (Actually, these discrepancies are a manifestation of incorrect model statistics and may cause problems in pure statistical assimilation methods of which we shall give an illustrative example later on.) When compared with the reference run, the spectral energy densities resulting from the assimilation experiment are consistently closer to the Geosat data for all wavenumbers. However, the assimilation cannot prevent the model spectra from dropping rapidly for wavelengths shorter than $150-200 \mathrm{~km}$. As pointed out by Böning and Budich [1992], this is about the scale where for a $1 / 3^{\circ}$ resolution model with biharmonic parameterization of lateral turbulent mixing, dissipative control becomes dominant. Assuming geostrophically related surface fields, the dominance of biharmonic friction would result in a spectral relation approaching $k^{-10}$, which can indeed be observed. It is very likely that a model with higher horizontal resolution, which would allow shifting the frictional regime to smaller scales, can extract much more information from altimetric data, particularly on the mesoscale!

The predominant effect of model friction on small scales can also be seen in instantaneous fields of sea surface height: Figure 9 displays SSH maps for a small region of the Gulf Stream extension for the CME model with no data assimilated (Figure 9a), Geosat SSH residuals plus model climatology mapped onto the model grid (Figure 9b) (in contrast to Figure 5 of an entire 17-day repeat period), and the assimilation experiment (Figure $9 \mathrm{c}$ ). The positions of a cold core ring near $56^{\circ} \mathrm{W}$ and a large meander at about $53^{\circ} \mathrm{W}$ are represented quite accurately, but the SSH map of the assimilation experiment is considerably smoother than the corresponding one produced from the Geosat data set itself. While this demonstrates that the assimilation can indeed reproduce the phase of individual mesoscale features very well, it is also evident that the model in its present $1 / 3^{\circ}$ resolution version is not fully appropriate for a quantitative representation of mesoscale processes.

When assimilating altimeter data we are not only interested in bringing the surface fields of the model closer to the observations, but we also would like to obtain an improved description of the deep ocean's hydrographic state. To investigate this matter in greater detail, we shall as an example analyze an individual state of the numerical ocean model. The state cho- 

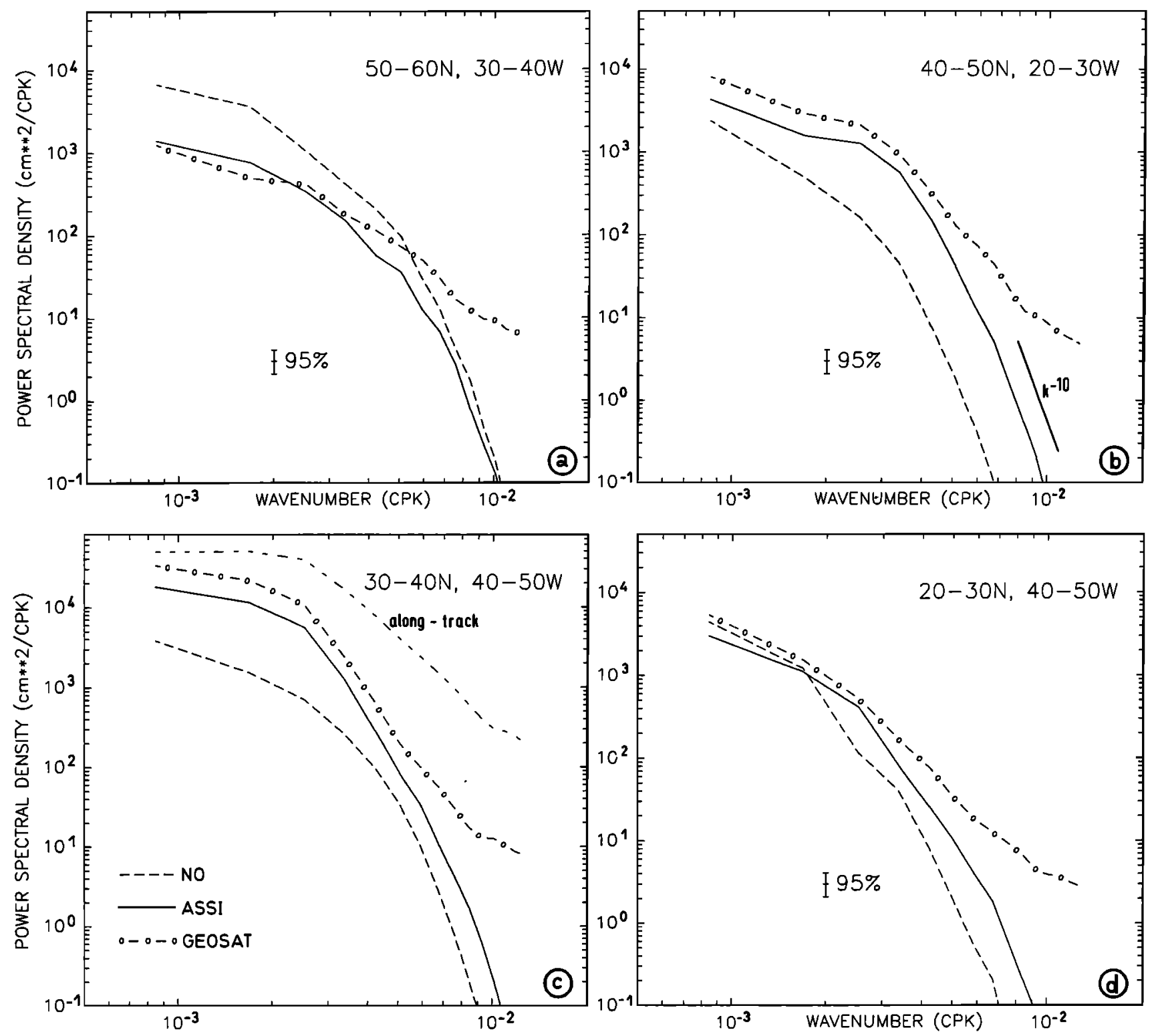

Figure 8. Meridional wavenumber spectra of sea surface height anomalies in $10^{\circ}$ by $10^{\circ}$ boxes. (a) Irminger Sea $\left(50^{\circ}-60^{\circ} \mathrm{N}, 30^{\circ}-40^{\circ} \mathrm{W}\right)$, (b) northeastern Atlantic $\left(40^{\circ}-50^{\circ} \mathrm{N}, 20^{\circ}-30^{\circ} \mathrm{W}\right)$, (c) northern boundary of the subtropical gyre $\left(30^{\circ}-40^{\circ} \mathrm{N}, 40^{\circ}-50^{\circ} \mathrm{W}\right)$, (d) southern part of the subtropical gyre $\left(20^{\circ}-30^{\circ} \mathrm{N}, 40^{\circ}-50^{\circ} \mathrm{W}\right)$. Spectra shown refer to Geosat data, the model with no data assimilated (NO), and to the assimilation experiment (ASSI). For reference, a corresponding along-track spectrum is shown in Figure 8c (from Stammer and Böning [1992]).

sen is the model hindcast for March 19,1987, and corresponds to the surface height fields shown in Figure 9. It virtually coincides with the hydrographic section shown in Figure 10a, which was taken by Krauss et al. [1990] during the period March 23 to April 1, 1987. Along this section, a cold core ring was surveyed near $38^{\circ} \mathrm{N}, 56^{\circ} \mathrm{W}$. This Gulf Stream ring can also be identified in the Geosat data (Figure 9b).

The efficiency of the assimilation procedure on extrapolating surface information into the ocean interior can now be demonstrated by comparing these independent hydrographic data with the results obtained from the assimilation experiment. The corresponding (same time and same location) temperature section of the assimilation experiment is shown in Figure $10 \mathrm{~b}$, that of the reference run in Figure 10c. Obviously, neither the reference run nor the assimilation run can reproduce the sharp horizontal temperature gradients of the hydrographic data. Furthermore, both model states systematically overestimate the depth of the mixed layer. While we expect that data other than observations of sea surface height will be required to obtain better estimates of the mixed layer depth (e.g., accurate wind forcing, SST measurements, hydrographic data), the problem of generally too weak horizontal gradients cannot be overcome in the present model resolution, with its only 25 model grid points on the 875-km-long section shown in Figure 10. However, we find that the assimilation of altimeter data leads to a clearly improved description of the thermocline structure: Not only does the assimilation run produce a reasonable hindcast of the doming of the thermocline associated 

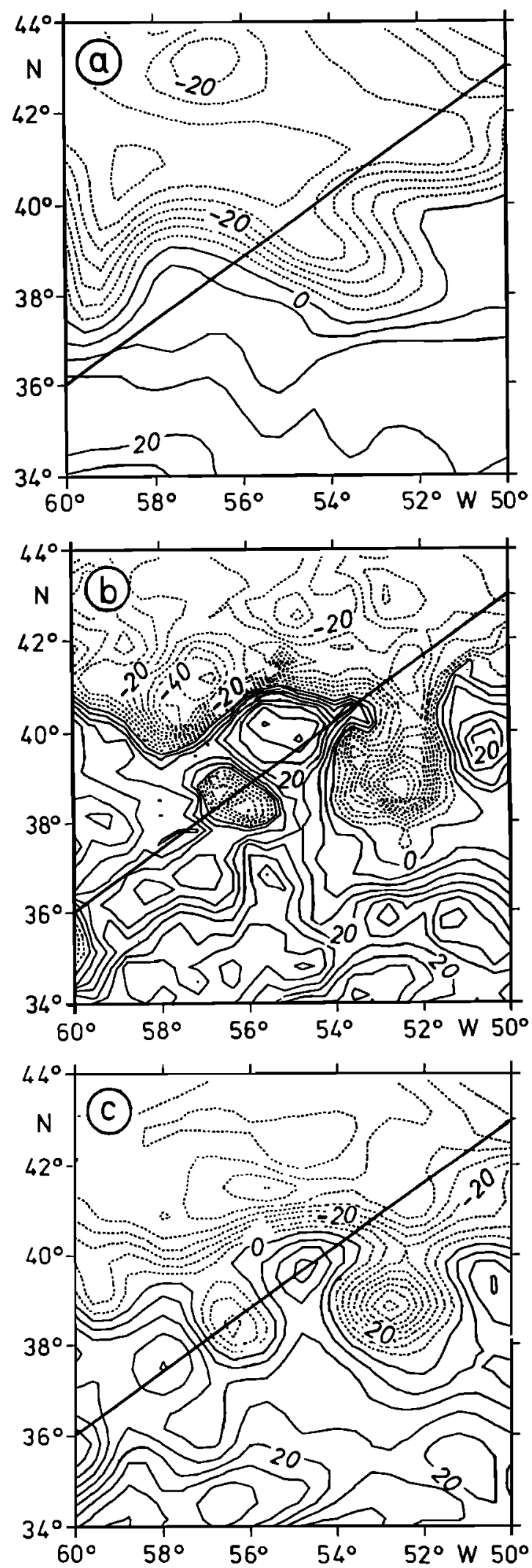

Figure 9. Sea surface height on March 19, 1987. (a) CME model when no data are assimilated, (b) model climatological mean plus SSH anomaly estimated from Geosat data of the 17-day period March 11-27. (c) Hindcast of the assimilation experiment. Contour interval is $5 \mathrm{~cm}$. Also indicated in all figures is the cruise track of $\mathrm{R} / \mathrm{V}$ Poseidon, along which the sections shown in Figures 10 and 11 were obtained.
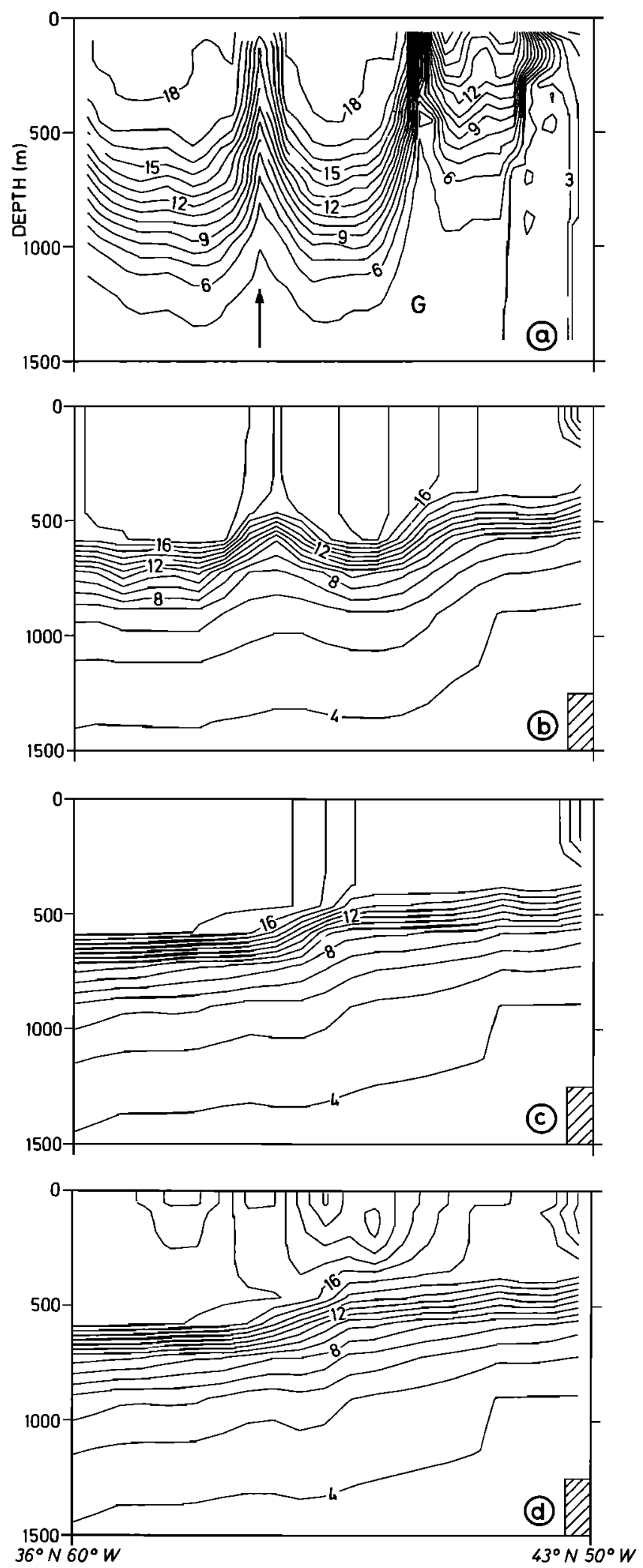

Figure 10. Potential temperature section along a straight line running from $36^{\circ} \mathrm{N}, 60^{\circ} \mathrm{W}$ to $43^{\circ} \mathrm{N}, 50^{\circ} \mathrm{W}$. (a) Hydrographic section of R/V Poseidon (described by Krauss et al. [1990]) with the position of the cold core ring marked by an arrow, that of the Gulf Stream by "G", (b) hindcast of the assimilation experiment, (c) reference run with no data assimilated, (d) pure linear regression estimate. 
with the cold core ring, albeit of underestimated magnitude, it also gives a good account of the changed position in the meandering Gulf Stream. In this respect, we think that despite the shortcomings of the circulation model and the relatively simple, suboptimal assimilation method, there is encouraging agreement between assimilation experiment and independent data along this hydrographic section.

For comparison we also show the results from an experiment employing a purely statistical vertical extrapolation method very similar to the one proposed by Mellor and Ezer [1991]. Local vertical correlations between directly measured surface properties and the prognostic model variables are used to project the observations onto state space. In particular, regression coefficients $R_{T}$ and $R_{S}$, which relate temperature and salinity to sea surface height itself, are computed from the model climatology:

$$
R_{T}=\langle\delta T \delta \eta\rangle /\left\langle(\delta \eta)^{2}\right\rangle, \quad R_{S}=\langle\delta S \delta \eta\rangle /\left\langle(\delta \eta)^{2}\right\rangle .
$$

Shown in Figure 10d is the statistically estimated temperature field $\rho^{\text {est }}=\rho\left(T^{\text {est }}, S^{\text {est }}\right)$ and $T^{\text {est }}$ with

$$
T^{\mathrm{est}}=T^{f}+\mu_{T}\left[\langle T\rangle+R_{T} \delta \eta^{\mathrm{obs}}-T^{f}\right],
$$

where $\mu_{T}=C_{T, \eta}^{2}\left(1-r_{\eta}\right)$. (See equation (A9) in the appendix.)

Perhaps the most striking feature of the hydrography resulting from this linear regression method is the large changes in temperature (and also salinity and density) close to the surface. Just three grid points west of the section shown in Figure 10d, near-surface temperature estimates even exceed $27^{\circ} \mathrm{C}$ ! For the Gulf Stream extension, such water mass properties can certainly not be considered as realistic values. This deficiency of the statistical regression scheme can readily be attributed to the use of regression coefficients computed from the model statistics. As discussed above, these statistics are inaccurate if only for the reason that the model considerably underestimates the surface height variability. There is simply no guarantee that an extrapolation of the simple linear regression (19) to such altimeter measurements that considerably exceed the range of sea level fluctuations simulated by the original model will give physically reasonable temperature estimates. Because of the physical constraints on temperature and also salinity to closely match the regional distribution of water masses, any linear relationship between water mass properties and sea surface height will be rather local in $\theta-S$ space, and one should be extremely reluctant to further extrapolate it. In this respect, the regression coefficients of the horizontal velocity components used in the previously developed reinitialization scheme (6), which may be viewed as representing the average superposition of different vertical modes, are believed to depend much less on the typical amplitudes of the surface velocity anomalies. To summarize these results, it can be concluded that one should as far as possible avoid tying uncertain model statistics into assimilation procedures, as long as numerical models of the ocean circulation still exhibit considerable systematic deficiencies.

To finally illustrate the important role of the circulation model for absorbing and dynamically interpolating the intermittent altimetric observations, another set of potential temperature sections is shown in Figure 11. For time and location again corresponding to the R/V Poseidon section of Figure 10a, Figure 11a displays the result of a single reinitialization step. The model forecast was taken from the reference run as shown
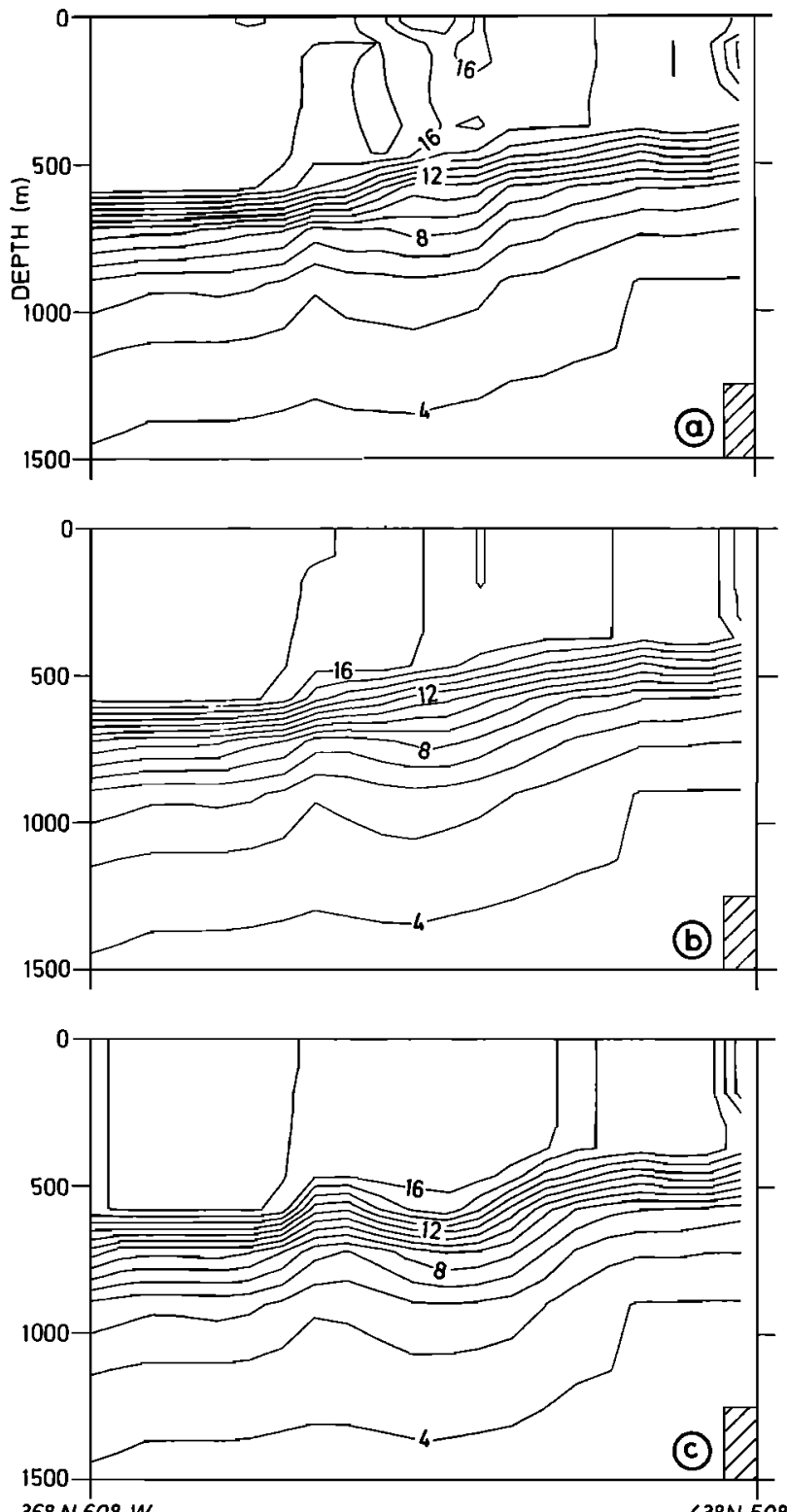

$36^{\circ} \mathrm{N} 60^{\circ} \mathrm{W}$

$43^{\circ} \mathrm{N} 50^{\circ} \mathrm{W}$

Figure 11. Potential temperature section along a straight line running from $36^{\circ} \mathrm{N}, 60^{\circ} \mathrm{W}$ to $43^{\circ} \mathrm{N}, 50^{\circ} \mathrm{W}$ (as Figure 10), (a) after single assimilation step, (b) after two assimilation cycles, i.e., 10 days of assimilation, and (c) after five assimilation cycles, i.e., 25 days of assimilation. The corresponding picture after 15 assimilation cycles is shown in Figure $10 \mathrm{~b}$.

in Figure 10c, the Geosat map is that of Figure 5. Recalling that the impact of the assimilation step is proportional to the model-data difference (see equation (2)), it is evident that despite starting from a completely wrong model forecast, i.e., the "worst" case, a single assimilation step leads to only moderate improvement of that state. Figure $11 b$ shows the situation after two successive assimilation cycles, i.e., the model hindcast with the assimilation turned on 10 days before taking the hydrographic snapshot. Still, there is only little signal of the cold core ring or the shifted Gulf Stream front. As can be seen from Figure 11c, this has changed after five assimilation cycles, i.e., 25 days after starting the assimilation. Obviously, the quality of the model hindcast improves with increasing length of the 
assimilation run. Note in particular, that in contrast to the evolution of the surface height rms error (Figure 6), the representation of the thermal structure still improves even after 25 days as can be seen by comparing Figure $11 \mathrm{c}$ with the hindcast obtained after assimilating for 78 days (Figure 10b).

\section{Conclusions}

The present study has demonstrated that the assimilation of satellite altimeter data into a basin-scale, eddy-resolving primitive equation model is feasible and, when applied correctly, can indeed provide new information about the state of today's ocean. Because of the immense computational requirements of statistically optimal methods like the Kalman filter or the adjoint method, one is restricted to adopt much simpler assimilation methods. To still utilize the information in the altimeter data properly, some direct extrapolation of the surface observations into the ocean interior is required.

The reinitialization method presented in this study was specially constructed to constrain any changes in the model's hydrographic state in a physically sensible way. The explicit extrapolation of the observed model-data misfit is restricted to those variables that do have a dynamical effect on the surface height field, namely, density and velocity. After a dynamically self-consistent estimate of these fields has been obtained, the computed density increment is partitioned into corrections to the prognostic model fields temperature and salinity. This partition explicitly conserves potential temperature and salinity on isopycnals at individual assimilation steps, thereby avoiding unnecessary distortions of the modeled water mass properties.

It was shown that the assimilation of Geosat altimeter data could considerably improve the spatial distribution of surface height variability. However, in order to fully assess the potential role of data assimilation in oceanography, one certainly has to investigate the effect of the assimilation procedure on other fields, such as temperature, salinity, and current velocities. Indeed, it turned out that the reinitialization method was able to produce a more reasonable hydrographic picture of the ocean. The high degree of realism reached by the reinitialization method was illustrated by the quite satisfactory reproduction of the doming of the thermocline associated with a cold core ring, which agreed well with independent hydrographic observations reported by Krauss et al. [1990]. Since only sea surface height measurements were assimilated, this is a remarkable success which emphasizes the additional gain of information resulting from the combination of data with dynamical models.

Of further interest for future applications of the reinitialization method is its property of conserving temperature and salinity on isopycnals. By improving the model's capability to accurately reproduce location and structure of cyclonic anomalies and frontal systems, the assimilation of altimeter data can inherently control the temporal and spatial setting of water mass modification associated with these dynamical features. With temperature and salinity of the newly formed water essentially being fixed by the atmospheric conditions in the formation area, these properties will not be changed by subsequent reinitialization steps. In this way the assimilation of SSH anomalies can lead to an improved mean hydrography of the model, which in turn will influence the mean currents. Such changes in the model mean have indeed been observed to occur in our assimilation experiment. A more detailed analysis of the underlying mechanisms (changes in water mass forma- tion, action of Reynolds stresses) is under way and will be reported in a future paper.

It is probably true that only by coupling the forthcoming continuous flow of accurate oceanic data with sophisticated numerical models will oceanographers be able to obtain a fully consistent description of the world ocean evolving in time. Eventually, the operational assimilation of any kind of observations will provide an indispensable tool for monitoring, understanding, and possibly predicting the changing climate of our ocean planet. The present work, which comprises the first successful assimilation of real altimeter data into a basin-scale eddy-resolving ocean model with active thermodynamics, is meant to be a basic contribution to this ambitious plan.

\section{Appendix: Derivation of the Weighting Coefficients}

In this appendix a brief derivation of the weighting coeffcients $\mu_{u}$ and $\mu_{\rho}$ will be given. These coefficients were introduced in section 2.2 as elements of the diagonal weighting matrix $B$. They are used in the update equations, e.g., for the eastward velocity component

$$
u^{a}=u^{f}+\mu_{u} R_{u}\left(u_{g}^{\mathrm{obs}}-u_{g}^{f}\right),
$$

with $u_{g}^{\text {obs }}-u_{g}^{f}=\Delta u_{g}$ given by (3).

The statistically optimal $\mu_{u}$ would minimize the expected error variance $\left\langle\varepsilon^{2}\left(u^{a}\right)\right\rangle$ of the analyzed (or updated) velocity, where we have defined $\varepsilon(\cdots)=(\cdots-u)$ as the difference relative to the (unknown) true velocity $u$, and $\langle\cdots\rangle$ denotes the expectation value. Using (A1), the expected analysis error variance can be described by

$$
\begin{aligned}
\left\langle\varepsilon^{2}\left(u^{a}\right)\right\rangle= & \left\langle\varepsilon^{2}\left(u^{f}\right)\right\rangle+2 \mu_{u}\left\langle\varepsilon\left(u^{f}\right)\left[\varepsilon\left(R_{u} u_{g}^{\mathrm{obs}}\right)-\varepsilon\left(R_{u} u_{g}^{f}\right)\right]\right\rangle \\
& +\mu_{u}^{2}\left\langle\left[\varepsilon\left(R_{u} u_{g}^{\mathrm{obs}}\right)-\varepsilon\left(R_{u} u_{g}^{f}\right)\right]^{2}\right\rangle
\end{aligned}
$$

Note that the last two terms include the error of the pseudo

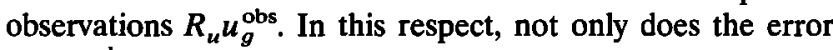
$\varepsilon\left(R_{u} u_{g}^{\text {obs }}\right)$ describe the error of the observed surface velocities, but it also accounts for the error introduced by the simple linear regression scheme used to vertically extrapolate surface data into the ocean interior. This extrapolation error is due to the fact that a linear regression can only explain the fraction $C^{2}$ (in the above example the squared correlation $C_{u, u_{g}}^{2}$ between surface and deep velocities) of the variance of the dependent variable ( $u$ in this case):

$$
\operatorname{Var}\left(R_{u} u_{g}\right)=C_{u, u_{g}}^{2} \operatorname{Var}(u)
$$

Hence the variance that can not be explained by the linear regression scheme is

$$
\left(1-C_{u, u_{g}}^{2}\right) \operatorname{Var}(u)=\frac{1-C_{u, u_{g}}^{2}}{C_{u, u_{g}}^{2}} \operatorname{Var}\left(R_{u} u_{g}\right) .
$$

The error variance of the pseudo observation $R_{u} u_{g}^{\text {obs }}$ then becomes

$\left\langle\varepsilon^{2}\left(R_{u} u_{g}^{\mathrm{obs}}\right)\right\rangle=R_{u}^{2}\left(\varepsilon^{2}\left(u_{g}^{\mathrm{obs}}\right)\right\rangle+\frac{1-C_{u, u_{g}}^{2}}{C_{u, u_{g}}^{2}} R_{u}^{2} \operatorname{Var}\left(u_{g}^{\mathrm{obs}}\right)$,

where the first term on the right describes the downward projection of the observational error at the surface and the second term accounts for the systematic error of the regression scheme. The latter term vanishes only for perfect correlations 
$C_{u, u_{g}}^{2}=1$, i.e., when there is a linear relationship between surface and deep velocities, whereas the linear regression will provide an exact projection of surface information into the ocean interior.

The weighting coefficient $\mu_{u}$ that minimizes the analysis error can be found by setting $\partial\left\langle\varepsilon^{2}\left(u^{a}\right)\right\rangle / \partial \mu_{u}=0$. Assuming that observational and forecast errors are uncorrelated and approximating $\left\langle\varepsilon\left(u^{f}\right) \varepsilon\left(R_{u} u_{g}^{f}\right)\right\rangle$ by $\left\langle\varepsilon^{2}\left(u_{g}^{f}\right)\right\rangle$ Var $(u) / \operatorname{Var}\left(u_{g}\right)$, we obtain

$$
\mu_{u}=\frac{\left\langle\varepsilon^{2}\left(u_{g}^{f}\right)\right\rangle}{C_{u, u_{g}}^{2}\left[\left\langle\varepsilon^{2}\left(u_{g}^{\mathrm{obs}}\right)+\left\langle\varepsilon^{2}\left(u_{g}^{f}\right)\right\rangle\right]+\left(1-C_{u, u_{g}}^{2}\right) \operatorname{Var}\left(\Delta u_{g}\right)\right.},
$$

where the identity $R_{u}^{2}=C_{u, u_{g}}^{2} \operatorname{Var}(u) / \operatorname{Var}\left(u_{g}\right)$ has been used (see equation (14)). It remains a main difficulty to estimate the model forecast error variance $\left\langle\varepsilon^{2}\left(u_{g}^{f}\right)\right)$. Because it is well known that numerical circulation models in general will not only exhibit statistical but also systematic errors (e.g., incorrect representation of the Gulf Stream separation), we make the rather conservative choice and approximate $\left\langle\varepsilon^{2}\left(u_{g}^{f}\right)\right\rangle$ by the variance of the geostrophic surface currents, $\operatorname{Var}\left(u_{g}\right)$, of the unperturbed model (see also the discussion in section 2.2). Expression (A6) then becomes

$\mu_{u}$

$$
=\frac{1}{C_{u, u_{g}}^{2}\left(\left\langle\varepsilon^{2}\left(u_{g}^{\mathrm{obs}}\right)\right) / \operatorname{Var}\left(u_{g}\right)+1\right)+\left(1-C_{u_{,} u_{g}}^{2}\right) \operatorname{Var}\left(\Delta u_{g}\right) / \operatorname{Var}\left(u_{g}\right)} .
$$

For $\operatorname{Var}\left(\Delta u_{g}\right) / \operatorname{Var}\left(u_{g}\right)=2$, i.e., the variance of the modeldata misfit being equal to the difference between two completely independent states of the unperturbed model, this can be reduced to

$$
\mu_{u}=\frac{1}{2-C_{u_{,} u_{g}}^{2}\left[1-\left\langle\varepsilon^{2}\left(u_{g}^{\mathrm{obs}}\right)\right\rangle / \operatorname{Var}\left(u_{g}\right)\right]} .
$$

Note that $\mu_{u}=1$ for perfect observations $\left(\left\langle\varepsilon^{2}\left(u_{g}^{\text {obs }}\right)\langle=0)\right.\right.$ and perfect correlations $\left(C_{u, u_{g}}^{2}=1\right)$. In this case, the model forecast is replaced by the accurate (pseudo) observations. If on the other hand either $C_{u, u_{u}}^{2}=0$ (in this case we also have $R_{u}=0$, and $\mu_{u}$ is not really important $)$ or $\left(\left\langle\varepsilon^{2}\left(u_{g}^{\text {obs }}\right)\right\rangle /\right.$ Var $\left.\left(u_{g}\right)\right)$, the weighting coefficient becomes $\mu_{u}=1 / 2$. Since in the absence of relevant altimetric data the SSH mapping algorithm produces just the climatological mean surface height, $\mu=1 / 2$ tends to minimize the analysis error by forcing the assimilation model toward climatology. Although climatology would, in this case, indeed be the state of minimum error, we shall at this point relax the minimum variance principle in order to put more weight on a self-consistent dynamical evolution of the circulation model. We therefore replace the above expression by

$$
\mu_{u} \simeq C_{u_{,} u_{g}}^{2}\left[1-\left\langle\varepsilon^{2}\left(u_{g}^{\mathrm{obs}}\right)\right\rangle / \operatorname{Var}\left(u_{g}\right)\right]
$$

which is identical to the leading term of a Taylor series expansion of (A8) about $C_{u, u_{g}}^{2}\left(1-\left\langle\varepsilon^{2}\left(u_{g}^{\text {obs }}\right)\right\rangle / \operatorname{Var}\left(u_{g}\right)\right)=1$ (i.e., perfect observations and perfect correlations). Still, $\mu_{u}=1$ for perfect observations and perfect correlations, but now $\mu_{u}=0$ if there is no relevant observational information.

In principle, it is possible to compute the expected relative error variance of the observed geostrophic surface currents, $\left\langle\varepsilon^{2}\left(u_{g}^{\text {obs }}\right)\right\rangle / \operatorname{Var}\left(u_{g}\right)$, from the estimated error variance of the mapped SSH residuals, $r_{\eta}=\left\langle\varepsilon^{2}\left(\eta^{\text {obs }}\right)\right\rangle /$ Var $\left(\eta^{\text {obs }}\right)$. However, for reasons of computational economy it was decided to approximate (A9) by the local expression

$$
\mu_{u}=C_{u, u_{g}}^{2}\left(1-r_{\eta}\right)^{2},
$$

where $r_{\eta}$ is provided by the SSH mapping routine (section 4).

As is described in section 2.2, the fact that computing the density increments $\Delta \rho$ involves vertical derivatives of the regression profiles $R_{u}$ and $R_{v}$ leads to a corresponding expression for the weighting coefficients for the density update,

$$
\mu_{\rho}=\min _{\substack{u_{\mathrm{up}}, u_{\mathrm{low}} \\ u_{\mathrm{up}}, u_{\mathrm{ow}}}}\left(C_{\ldots, u_{q}}^{2}\right)\left(1-r_{\eta}\right)^{2},
$$

where the subscripts up and low denote the vertical levels used for computing the individual $z$ derivative in (11).

Acknowledgments. This work has been supported by the Deutsche Forschungsgemeinschaft through the Sonderforschungsbereich 133, "Warmwassersphäre des Atlantiks," and by the EU MAST project, under contract MAS2-CT93-0060.

\section{References}

Arhan, M., and A. Colin de Verdière, Dynamics of eddy motions in the eastern North Atlantic, J. Phys. Oceanogr., 15, 153-170, 1985.

Beckmann, A., C. W. Böning, C. Köberle, and J. Willebrand, Effects of increased horizontal resolution in a simulation of the North Atlantic Ocean, J. Phys. Oceanogr., 24, 326-344, 1994a.

Beckmann, A., C. W. Böning, B. Brügge, and D. Stammer, On the generation and role of eddy variability in the central North Atlantic Ocean, J. Geophys. Res., 99, 20,381-20,391, 1994b.

Böning, C. W., Influences of rough bottom topography on flow kinematics in an eddy-resolving circulation model, J. Phys. Oceanogr., 19, 77-97, 1989.

Böning, C. W., and R. Budich, Eddy dynamics in a primitive equation model: Sensitivity to horizontal resolution and friction, J. Phys. Oceanogr., 22, 361-381, 1992.

Böning, C. W., and P. Herrmann, On the annual cycle of poleward heat transport in the ocean: Results from high-resolution modelling of the North and equatorial Atlantic, J. Phys. Oceanogr., 24, 91-107, 1994.

Bretherton, F., R. Davies, and C. Fandry, A technique for objective analysis and design of oceanographic experiments applied to MODE-73, Deep Sea Res., 23, 559-582, 1976.

Bryan, K., A numerical method for the study of the circulation of the world ocean, J. Comput. Phys., 4, 347-376, 1969.

Bryan, F. O., and W. R. Holland, A high-resolution simulation of the wind- and thermohaline-driven circulation in the North Atlantic Ocean, in Parameterization of Small-Scale Processes, Proceedings 'Aha huliko'a, Hawaiian Winter Workshop, pp. 99-115, Univ. of Hawaii, Honolulu, 1989.

Camp, N. T., and R. L. Elsberry, Oceanic thermal response to strong atmospheric forcing, 2, The role of one-dimensional processes, $J$. Phys. Oceanogr., 8, 215-224, 1978.

Cooper, M., and $\mathbf{K}$. Haines, Altimetric assimilation with water property conservation, J. Geophys. Res., 101, 1059-1077, 1996.

Cox, M. D., A primitive equation, 3-dimensional model of the ocean, GFDL Ocean Group Tech. Rep. 1, Geophys. Fluid Dyn. Lab., Princeton Univ., Princeton, N. J., 1984.

Cox, M. D., An eddy-resolving numerical model of the ventilated thermocline, J. Phys. Oceanogr., 15, 1312-1324, 1985.

De Mey, P., and Y. Ménard, Synoptic analysis and dynamical adjustment of GEOS 3 and Seasat altimeter eddy fields in the northwest Atlantic, J. Geophys. Res., 94, 6221-6231, 1989.

De Mey, P., and A. R. Robinson, Assimilation of altimeter data eddy fields in a limited-area quasi-geostrophic model, $J$. Phys. Oceanogr., 17, 2280-2293, 1987.

Didden, N., and F. Schott, Seasonal variations in the western tropical Atlantic: Surface circulation from Geosat altimetry and WOCE model results, J. Geophys. Res., 97, 3529-3541, 1992. 
Ezer, T., and G. L. Mellor, Continuous assimilation of Geosat altimeter data into a three-dimensional primitive equation Gulf Stream model, J. Phys. Oceanogr., 24, 832-847, 1994.

Fukumori, I., B. Benveniste, C. Wunsch, and D. B. Haidvogel, Assimilation of sea surface topography into an ocean circulation model using a steady-state smoother, J. Phys. Oceanogr., 23, 1831-1855, 1993.

Ghil, M., S. Cohn, J. Tavantzis, K. Bube, and E. Isaacson, Application of estimation theory to numerical weather prediction, in Dynamic Meteorology: Data Assimilation Methods, edited by L. Bengtson, $\mathrm{M}$. Ghil, and E. Källén, pp. 139-224, Springer-Verlag, New York, 1981.

Haines, $\mathrm{K}$., A direct method for assimilating sea surface height data into ocean models with adjustment to the deep circulation, J. Phys. Oceanogr., 21, 843-868, 1991.

Haines, K., P. Malanotte-Rizzoli, R. E. Young, and W. R. Holland, A comparison of two methods for the assimilation of altimeter data into a shallow water model, Dyn. Atmos. Oceans, 17, 89-133, 1993.

Han, Y.-J., A numerical world oceancirculation model, II, A baroclinic experiment, Dyn. Atmos. Oceans, 8, 141-172, 1984.

Hellerman, S., and $M$. Rosenstein, Normal monthly wind stress over the world ocean with error estimates, J. Phys. Oceanogr., 13, 10931104,1983

Holland, W. R., and P. Malanotte-Rizzoli, Assimilation of altimeter data into an ocean circulation model: Space versus time resolution studies, J. Phys. Oceanogr., 19, 1507-1534, 1989.

Hurlburt, H. E., Dynamic transfer of simulated altimeter data into subsurface information by a numerical ocean model, $J$. Geophys. Res., 91, 2372-2400, 1986.

Hurlburt, H. E., D. N. Fox, and E. J. Metzger, Statistical inference of weakly correlated subthermocline fields from satellite altimeter data, J. Geophys. Res., 95, 11,375-11,409, 1990.

Isemer, H.-J., and L. Hasse, The Bunker Climate Atlas of the North Atlantic Ocean, vol. 2, Air-Sea Interactions, 252 pp., Springer-Verlag, New York, 1987.

Kindle, J. C., Sampling strategies and model assimilation of altimetric data for ocean monitoring and prediction, J. Geophys. Res., 91 2418-2432, 1986

Krauss, W., R. H. Käse, and H.-H. Hinrichsen, The branching of the Gulf Stream southeast of the Grand Banks, J. Geophys. Res., 95, $13,089-13,103,1990$.

Le Traon, P. Y., M. C. Rouquet, and C. Boissier, Spatial scales of mesoscale variability in the North Atlantic as deduced from Geosat data, J. Geophys. Res., 95, 20,267-20,285, 1990.

Levitus, S., Climatological atlas of the world ocean, NOAA Prof. Pap. 13, 173 pp., U.S. Govt. Print. Off., Washington, D. C., 1982.

Mellor, G. L., and T. Ezer, A Gulf Stream model and an altimetry assimilation scheme, J. Geophys. Res., 96, 8779-8795, 1991.

Oschlies, A., Assimilation of satellite altimeter data into an eddyresolving primitive equation model of the North Atlantic Ocean, Ph.D. thesis, 131 pp., Inst. für Meeresk. Kiel, Germany, 1994.

Robinson, A. R., M. A. Spall, and N. Pinardi, Gulf Stream simulations and the dynamics of ring and meander processes, J. Phys. Oceanogr., $18,1811-1853,1988$.

Robinson, A. R., M. A. Spall, L. J. Walstad, and W. G. Leslie, Data assimilation and dynamical interpolation in Gulfcast experiments, Dyn. Atm. Oceans, 13, 301-316, 1989.

Sailor, R. V., and A. R. Le Schack, Preliminary determination of the Geosat radar altimeter noise spectrum, Johns Hopkins APL Tech. Dig., 8(2), 182-183, 1987.

Schott, F. A., and C. W. Böning, Evaluation of the WOCE model in the western equatorial Atlantic: Upper layer circulation, J. Geophys. Res., 96, 6993-7004, 1991.

Semtner, A. J., Finite-difference formulation of a world ocean model, in Advanced Physical Oceanographic Numerical Modelling, edited by J. J. O'Brian, pp. 187-202, D. Reidel, Norwell, Mass., 1986.

Stammer, D., Uber die mesoskalige Variabilität im Atlantischen Ozean, Analyse und Assimilation von Geosat-Altimeterdaten, Ph.D. thesis, 197 pp., Inst. für Meeresk., Kiel, Germany, 1992.

Stammer, D., and C. W. Böning, Mesoscale variability in the Atlantic Ocean from Geosat altimetry and WOCE high resolution numerical modeling, J. Phys. Oceanogr., 22, 732-752, 1992.

Stammer, D., H.-H. Hinrichsen, and R. H. Käse, Can meddies be detected by satellite altimetry?, J. Geophys. Res., 96, 7005-7014, 1991.

Verron, J., Nudging satellite altimeter data in quasi-geostrophic ocean models, J. Geophys. Res., 97, 7479-7491, 1992.

White, W. B., C.-K. Tai, and W. R. Holland, Continuous assimilation of Geosat altimetric sea level observations into a numerical synoptic ocean model of the California Current, J. Geophys. Res., 95, 31273148, 1990a.

White, W. B., C.-K. Tai, and W. R. Holland, Continuous assimilation of simulated Geosat altmetric sea level into an eddy-resolving numerical ocean model, 1, Sea level differences, J. Geophys. Res., 95, 3219-3234, $1990 \mathrm{~b}$.

White, W. B., C.-K. Tai, and W. R. Holland, Continuous assimilation of simulated Geosat altmetric sea level into an eddy-resolving numerical ocean model, 1, Referenced sea level differences, $J$. Geophys. Res., 95, 3235-3251, 1990c.

Willebrand, J., R. H. Käse, D. Stammer, H.-H. Hinrichsen, and W. Krauss, Verification of Geosat sea surface topography in the Gulf Stream extension with surface drifting buoys and hydrographic measurements, J. Geophys. Res., 95, 3007-3014, 1990.

Wunsch, C., The North Atlantic general circulation west of $50^{\circ} \mathrm{W}$ determined by inverse methods, Rev. Geophys., 16, 583-620, 1978.

A. Oschlies, GRGS/CNES, 18 Avenue Edouard Belin, 31055 Toulouse, France.

J. Willebrand, Institut für Meereskunde, Düsternbrooker Weg 20, 24105 Kiel, Germany.

(Received March 9, 1995; revised December 12, 1995; accepted December 13, 1995.) 